NUREG/CR-6220

SAND94-0769

\title{
An Assessment of Fire Vulnerability for Aged Electrical Relays
}

Prepared by

R. A. Vigil, S. P. Nowlen

Sandia National Laboratories

Operated by

Sandia Corporation

Prepared for

U.S. Nuclear Regulatory Commission 


\section{AVAILABILITY NOTICE}

Availability of Reference Materials Cited in NRC Publications

Most documents cited In NRC publications will be available from one of the following sources:

1. The NRC Public Document Room, 2120 L Street, NW., Lower Level, Washington, DC 20555-0001

2. The Superintendent of Documents, U.S. Government Printing Office, P. O. Box 37082, Washington, DC 20402-9328

3. The National Technical Information Service, Springfield, VA 22161-0002

Although the listing that follows represents the majority of documents cited in NRC publications, it is not intended to be exhaustive.

Referenced documents available for inspection and copying for a fee from the NRC Public Document Room include NRC correspondence and internal NRC memoranda; NRC bulletins, circulars, information notices, Inspection and investigation notices; licensee event reports; vendor reports and correspondence; Commission papers; and applicant and licensee documents and correspondence.

The following documents in the NUREG serles are available for purchase from the Government Printing Office: formal NRC staff and contractor reports, NRC-sponsored conference proceedings, international agreement reports, grantee reports, and NRC booklets and brochures. Also available are regulatory guides, NRC regulations in the Code of Federal Regulations, and Nuclear Regulatory Commission Issuances.

Documents avallable from the National Technical Information Service include NUREG-series reports and technical reports prepared by other Federal agencies and reports prepared by the Atomic Energy Commission, forerunner agency to the Nuclear Regulatory Commission.

Documents available from public and special technical libraries include all open literature items, such as books, journal articles, and transactions. Federal Register notices. Federal and State legislation, and congressional reports can usually be obtained from these libraries.

Documents such as theses, dissertations, foreign reports and translations, and non-NRC conference proceedings are avallable for purchase from the organization sponsoring the publication cited.

Single coples of NRC draft reports are available free, to the extent of supply, upon written request to the Office of Administration, Distribution and Mail Services Section, U.S. Nuclear Regulatory Commission, Washington, DC 20555-0001.

Coples of industry codes and standards used in a substantive manner in the NRC regulatory process are maintained at the NRC Library. Two White Flint North, 11545 Rockville Pike, Rockville, MD 20852-2738. for use by the public. Codes and standards are usually copyrighted and may be purchased from the originating organizatlon or, if they are American National Standards, from the American National Standards Institute, 1430 Broadway, New York, NY 10018-3308.

\section{DISCLAIMER NOTICE}

This report was prepared as an account of work sponsored by an agency of the United States Government. Neither the United States Government nor any agency thereof, nor any of their employees, makes any warranty, expressed or implied, or assumes any legal liability or responsibility for any third party's use, or the results of such use, of any information, apparatus, product, or process disclosed in this report, or represents that its use by such third party would not infringe privately owned rights. 


\section{An Assessment of Fire Vulnerability for Aged Electrical Relays}

Manuscript Completed: June 1994

Date Published: March 1995

Prepared by

R. A. Vigil, * S. P. Nowlen

Sandia National Laboratories

Albuquerque, NM 87185-0737

\section{Prepared for}

Division of Engineering Technology

Office of Nuclear Regulatory Research

U.S. Nuclear Regulatory Commission

Washington, DC 20555-0001

NRC Job Code A1833

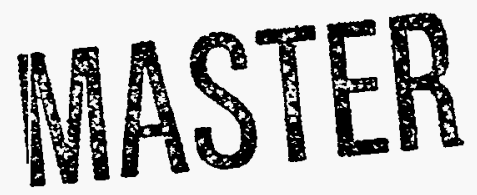

*Science \& Engineering Associates, Inc.

6100 Uptown Blvd. NE

Albuquerque, NM 87110

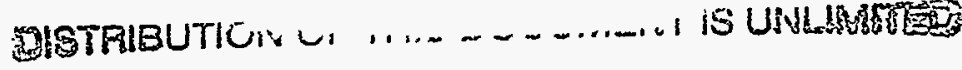

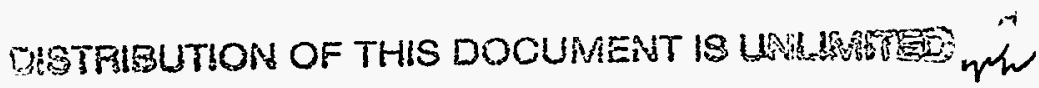




\begin{abstract}
This report details testing to assess the impact of aging on the fire vulnerability of Agastat and General Electric relays. Both aged and unaged relays were tested. Aged relays were subjected to operational cycling under rated load and thermally aged for sixty days. All relays were exposed to one of three different fire temperature profiles in the Severe Combined Environments Test Chamber located at Sandia National Laboratories. The ability to operate properly in the given fire environment was monitored. Results for the aged and unaged relays were examined to determine the impact of aging on the relays' ability to sustain operation under the test conditions. Overall results indicated that the aged relays' performance was not significantly different from that of the unaged relays.
\end{abstract}




\section{DISCLAIMER}

Portions of this document may be illegible in electronic image products. Images are produced from the best available original document. 


\section{Table of Contents}

Page

Executive Summary

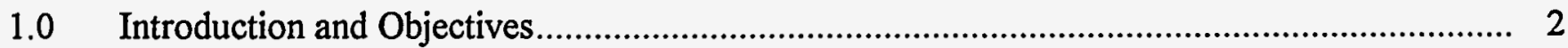

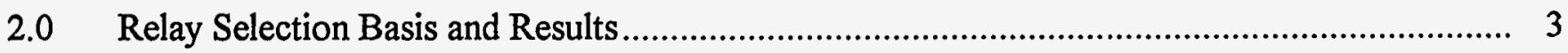

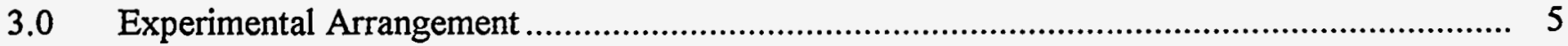

3.1 Relay Aging Procedures.............................................................................. 5

3.2 Relay Fire Testing........................................................................................ 5

3.3 Relay Operational Assessments................................................................. 7

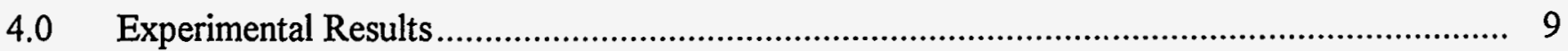

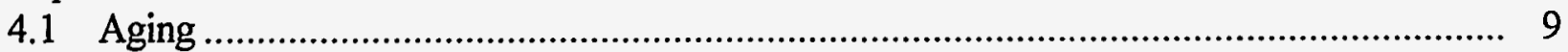

4.2 Thermal Exposure Results ................................................................... 9

4.2.1 Agastat GPI Results .................................................................. 10

4.2.2 General Electric HMA Results ............................................................. 11

4.2.3 General Electric HGA Results ........................................................ 12

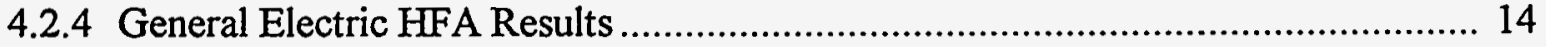

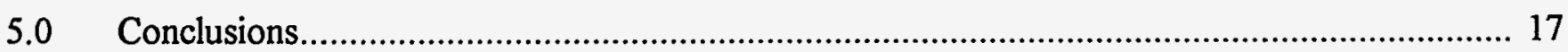

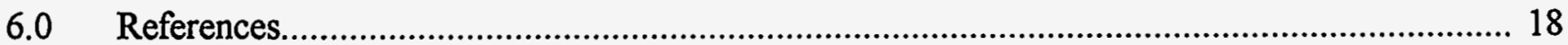

Appendix A SCETCh Temperature Exposure Plots for All Relays Tested.................................A-1 


\section{List of Figures}

Figure 1 Schematic of a typical armature style relay 3

Figure 2 Severe Combined Environments Test Chamber (SCETCh) at Sandia National Laboratories 5

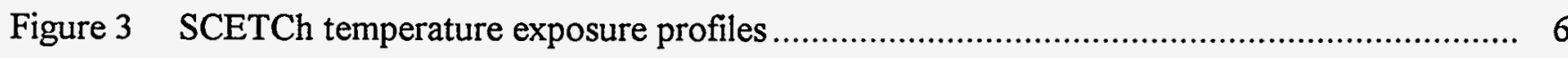

Figure 4 Measurement schematic for each contact pair and measurement matrix............................ 7

Figure 5 Agastat Al relay with normally open contact stuck because of a melted contact carrier...... 10

Figure 6 General Electric HMA Relay B-3 after thermal exposure .......................................... 12

Figure 7 General Electric HGA Relay C-1 failure of the spool's top plate.................................... 13

Figure 8 General Electric HGA Relay C-4 failure of the armature because of blockage ................... 14

Figure 9 General Electric HFA Relay D-1 after thermal exposure ............................................. 15

\section{List of Tables}

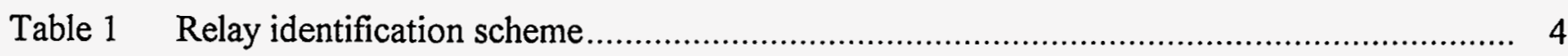

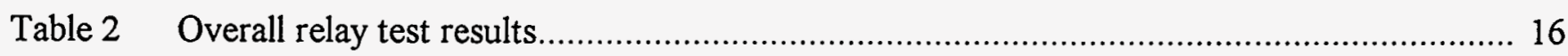




\section{Executive Summary}

The purpose of this test program was to assess whether the fire vulnerability of electrical relays increased with aging. The sequence followed for the test program was to: identify specific relay types, develop three fire scenarios, artificially age several relays, test the unaged and aged relays in the fire exposure scenarios, and compare the results.

The relays tested were Agastat GPI, General Electric (GE) HMA, HGA, and HFA. At least two relays of each type were artificially aged and at least two relays of each type were new. Relays were operationally aged by cycling the relay under rated load for 2000 operations. These relays were then thermally aged for 60 days with their coil energized.

Temperature exposure testing was conducted in Sandia's Severe Combined Environments Test Chamber (SCETCh). Three exposure profiles were developed for this test program, which were representative of a generic mild, moderate or severe thermal exposure. The exposure profiles consisted of two phases: The initial phase consisted of a temperature ramp to either $250^{\circ} \mathrm{C}$, $350^{\circ} \mathrm{C}$, or $450^{\circ} \mathrm{C}$, a $10-20$ minute dwell at the desired temperature, and then a temperature decrease toward ambient. The second phase began shortly after the end of the first phase and consisted of a temperature ramp at a rate of $10^{\circ} \mathrm{C}$ per minute until failure was observed. The second phase was only performed if the relay survived the first phase.

Results for the Agastat GPI relays indicated that aging would not significantly affect the thermal vulnerability of the relay. All of the relays tested were observed to fail at temperatures ranging from 206 to $250^{\circ} \mathrm{C}$. In fact, of the relays tested, only one-an aged sample-survived the initial phase of the mild exposure profile. Failures were generally traced to either the coil rectification circuit or the base socket.
Results for the GE HMA relays indicated that the aged samples were, in fact, somewhat more rugged than the unaged samples. During exposures to the moderate exposure profile, an unaged sample was observed to fail whereas an aged sample survived the initial phase of this profile. All failures were attributed to failure of the armature. In three of the four cases, actuation of the armature failed because of an accumulation of an unknown substance that formed on the top of the coil's spool just below the armature. The final failure was attributed to the armature becoming fused to the relay's housing.

Results for the GE HGA relays indicated that aging did not impact the thermal vulnerability of the relays. However, one of the aged samples displayed a unique failure in that it failed during the cool-down portion of the first phase of the moderate exposure profile. The remaining three relays survived to temperatures in excess of $450^{\circ} \mathrm{C}$. Three of the relay failures were attributed to the accumulation of an unknown substance that formed on the top of the coil's spool just below the armature. The final failure was attributed to deformation of the coil top plate.

Results for the GE HFA relays indicated that aging did not significantly impact the thermal vulnerability. Both aged and unaged samples were observed to survive the initial phase of the mild exposure profile while failing during the initial phase of the moderate exposure profile. All failures were attributed to failures of the armature.

In general, it was concluded that aging did not adversely affect the thermal vulnerability of relays. Depending on the type of relay, the effect of exposure to even mild temperature excursions $\left(>200^{\circ} \mathrm{C}\right)$ may degrade relay performance regardless of the relay's age. Failure mechanisms were generally attributed to failures in the armature. 


\subsection{Introduction and Objectives}

There has been some concern that, as nuclear power plants age, protective measures taken to control and minimize the impact of fire may become ineffective, or significantly less effective, and hence result in an increased fire risk. One objective of the Fire Vulnerability of Aged Electrical Components Program is to assess the effects of aging and service wear on the fire vulnerability of electrical equipment. An increased fire vulnerability of components may lead to an overall increase in fire risk to the plant.
Because of their widespread use in various electrical safety systems, electromechanical relays were chosen to be the initial components for evaluation [1]. This test program assessed the impact of operational and thermal aging on the vulnerability of these relays to fire-induced damage. Only thermal effects of a fire were examined in this test program. The impact of smoke, corrosive materials, or fire suppression effects on relay performance were not addressed in this test program. 


\subsection{Relay Selection Basis and Results}

An earlier study performed as a part of the Fire Vulnerability of Aged Electrical Components Program identified and prioritized nuclear power plant electrical equipment potentially vulnerable to age-related increases in fire vulnerability[1]. This study included an evaluation of industry practices and component count totals. As a result, relays were identified as one of the high priority components.

Relays used in safety-related applications can typically be divided into four categories: protective, auxiliary, control, and timing. Protective relays serve to protect electrical distribution systems from electrical overloads. Auxiliary relays serve to assist protective relays, especially when loads up to $35 \mathrm{amps}$ are present in the distribution system. Control relays serve as direct controlling mechanisms for various mechanical components. Timing relays perform similarly to control relays with the exception that these relays are combined with a timing device that actuates the contacts after a time period has passed from the receipt of a control signal [2].

The dominant aging-related stress for relays identified in Reference 1 is the thermal aging of synthetic parts caused by continuous energization or elevated cabinet temperatures. Reference 1 also identifies the following possible failure modes and causes:

\section{Relay Failure Modes:}

- Failure to actuate when commanded

- Actuates without command

- Does not make or break current

- Failure to carry current

- High contact resistance

- Set-point shift

- Time delay shift

Relay Failure Causes:

- Phase-to-ground short

- Coil insulation breakdown

- Contact wear

- Binding of contacts because of carrier warpage
- Pitting, corrosion, and accumulation of contaminants on contacts

- Wear of moving parts

- Loss of integrity of relay pin/socket connection

- Vibration damage: contact chatter, loosening of connections

- Shift in resistance and capacitive values affecting time delay and relay set-point values

Reference 1 identifies those relay models having the greatest numbers in nuclear power plants. In particular, three General Electric (GE) models are identified as the most widely used in industry: the GE model HFA (21\%), GE model HGA (12\%), and GE model HMA (7\%). General Electric supplies approximately $52 \%$ of all electromechanical relays to the utilities that responded to the survey[1], which also noted that Agastat/Amerace relays provided $10 \%$ of all relays. In light of the survey results, the following relays were chosen to be tested in this program:

- General Electric 12HFA51A49F

- General Electric 12HMA111A9

5 relays tested

- General Electric 12HGA11A70F

- Agastat/Amerace GPI 4 relays tested 4 relays tested 6 relays tested

All the relays chosen are armature style relays and are rated for operation at $115 \mathrm{~V}$ and $12 \mathrm{amps}$ (except for the Agastats which are rated at 10 amps). Figure 1 shows the basic components of a typical armature style relay.

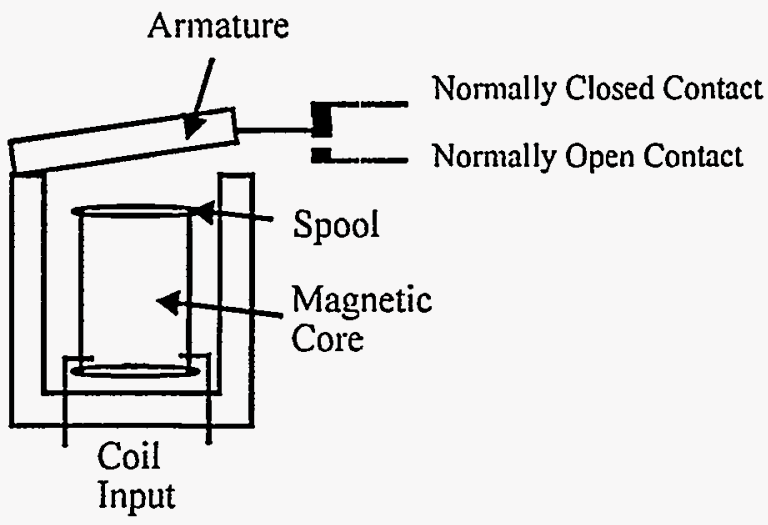

Figure 1 Schematic of a typical armature style relay

The relays tested in this program were obtained directly from the suppliers. They are effectively 


\section{Relay Selection}

identical to UL recognized and Class $1 \mathrm{E}$ qualified devices sold to nuclear power plants, although they were not procured to Class $1 \mathrm{E}$ specifications. The major difference lies in the traceability of the relay production.

General Electric relays are constructed with either the standard life coil design or the Century series coil design. Further analysis of the survey data from Reference 2 indicates that both types of coil designs for these relay models are in use in various systems in nuclear power plants. The GE HGA and $\mathrm{HFA}$ relays tested in this program were constructed using the standard life relay coil design. The GE HMA models tested in this program were constructed using the Century Series coil design.

Basic design features of the Century Series coil include the following: the coil's spool is comprised of high thermal strength, glass-filled polyester for extended life at elevated temperatures; the wire insulation is a polyamideimide wire coating $\quad\left(180^{\circ} \mathrm{C}\right.$ rating $)$ that retains insulation integrity and mechanical strength at elevated temperatures; the encapsulation is described by the manufacturer as polybutadiene, solventless, and impregnant.

Table 1 Relay identification scheme
Accelerated life tests conducted at an elevated temperature and maximum voltage have established a projected service life of 40 years at $55^{\circ} \mathrm{C}$ and $110 \%$ of rated voltage for this coil design. The standard life coils are simple coil designs with a phenolic spool and an exterior tape wrap. The wire insulation is similar to that of the Century Series.

The Agastat GPI relays are constructed using an electromagnetic core. A W-shaped mechanism is connected to the core to provide contact switching movement. The coil provides a low mean turn length and assists in heat dissipation. The GPI relays also have a built-in rectification circuit that retains the dc efficiency of the electromagnet. The current peak upon coil energization is also eliminated through the use of a capacitor. The GPI relays require a screw terminal molded socket for operation. Note that there are two socket models available. The model number of the socket used in this test program was CR0067.

In all, 19 relays were tested as a part of this program. Table 1 lists the scheme used to identify each of the relays tested.

\begin{tabular}{|c|c|c|}
\hline Relay Identification & Model Number & Aging Condition \\
\hline A1 & Agastat GPI & Aged \\
\hline A2 & Agastat GPI & Aged \\
\hline A3 & Agastat GPI & Unaged \\
\hline A4 & Agastat GPI & Unaged \\
\hline A5 & Agastat GPI & Unaged \\
\hline A6 & Agastat GPI & Unaged \\
\hline B1 & GE 12HMA111A9 & Aged \\
\hline B2 & GE 12HMA111A9 & Aged \\
\hline B3 & GE 12HMA111A9 & Unaged \\
\hline B4 & GE 12HMA111A9 & Unaged \\
\hline C1 & GE 12HGA11A70F & Aged \\
\hline C2 & GE 12HGA11A70F & Unaged \\
\hline C3 & GE 12HGA11A70F & Unaged \\
\hline C4 & GE 12HGA11A70F & Aged \\
\hline D1 & GE 12HFA51A49F & Aged \\
\hline D2 & GE 12HFA51A49F & Unaged \\
\hline D3 & GE 12HFA51A49F & Unaged \\
\hline D4 & GE 12HFA51A49F & Unaged \\
\hline D5 & GE 12HFA51A49F & \\
\hline
\end{tabular}




\subsection{Experimental Arrangement}

\subsection{Relay Aging Procedures}

A general aging procedure was established based on the information contained in IEEE C37.1051987, Standard for Qualifying Class 1E Protective Relays. This procedure included both operational and thermal aging. Radiation aging of the relays was not included in the aging procedure.

The relays to be aged were cycled individually under rated load for 2000 cycles to fulfill the basic operational aging requirements defined in IEEE C37.105-1987. The relay coils were energized every minute for 0.4 seconds. After each set of 500 cycles, the coil resistance was measured for each relay.

After completion of the operational aging, the relays were thermally aged in an oven for 60 days at $110^{\circ} \mathrm{C}$. During this entire period, the coil of each relay was energized to simulate the additional thermal load produced by the self-heating effects of the coil. (Note that the two
Agastat bases were not included with the relays in the thermal aging portion of the test.)

The thermal aging was intended to provide for a generic aging condition for the relays overall, not a specific aged condition for any one of the various relay materials. If an activation energy of $1.15 \mathrm{eV}$ is assumed (typical of polymers) then the aging conditions would be equivalent to 40 years of exposure at a $58{ }^{\circ} \mathrm{C}$ ambient.

\subsection{Relay Fire Testing}

The fire exposure tests were conducted in Sandia National Laboratories' (SNL's) Severe Combined Environments Test_Chamber (SCETCh). The SCETCh facility, shown in Figure 2, is able to simulate both transient and steady-state thermal conditions. The SCETCh facility was designed to simulate fire environment effects. Additional capabilities of the SCETCh facility include steam testing and hydrogen burn simulation. It may be used as a high temperature/pressure vessel. The

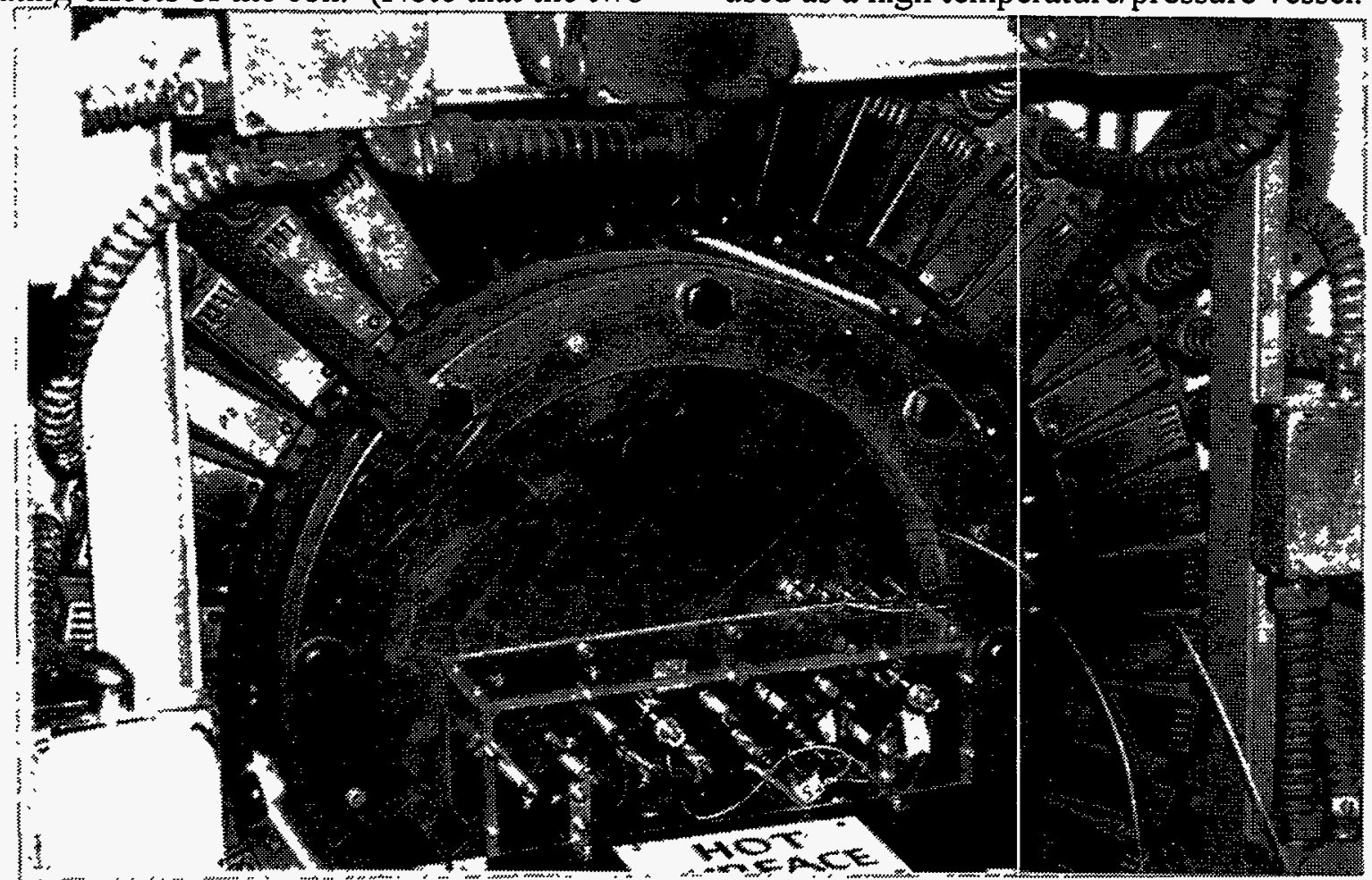

Figure 2 Severe Combined Environments Test Chamber (SCETCh) at Sandia National Laboratories 


\section{Experimental Arrangement}

SCETCh facility is designed to operate at elevated temperatures as high as $1500^{\circ} \mathrm{C}$.

The SCETCh chamber is a cylindrical chamber measuring 24 -inches long by 18 -inches in diameter. The shell and cover plates are constructed from Inconel 625 . The elevated temperatures are generated by a series of quartz lamps mounted around the chamber. Resistance coil heaters are used to heat incoming fresh air for the chamber. The desired temperature exposure profiles are achieved using a computer-controlled 480 Vac power supply.

Each of the sample relays was tested using one of three thermal exposure profiles. These profiles were intended to be representative of generic mild, moderate, and severe thermal exposures, respectively. That is, the profiles were intended to represent various commonly identified generic fire scenarios, rather than any given specific fire scenario. Transient profile ramp rates, peak exposure temperatures, and profile durations were determined based on the results of available test data and actual nuclear power plant fire event reports.[3-7]

Each of the three profiles consists of two phases as shown in Figure 3. During the first phase of the exposure:

- the exposure temperature was increased from ambient at a rate of approximately $20^{\circ} \mathrm{C} / \mathrm{min}$ (initial ramp);

- upon attaining a predetermined temperature the exposure was held constant for a specified time (plateau);

- exposure temperature was then decreased toward ambient conditions over a period of approximately 20 minutes (cool-down).

For the mild exposure profile, the initial ramp lasted for approximately 10 minutes, reaching a plateau temperature of $250^{\circ} \mathrm{C}$, which was held for an additional 10 minutes. For the moderate

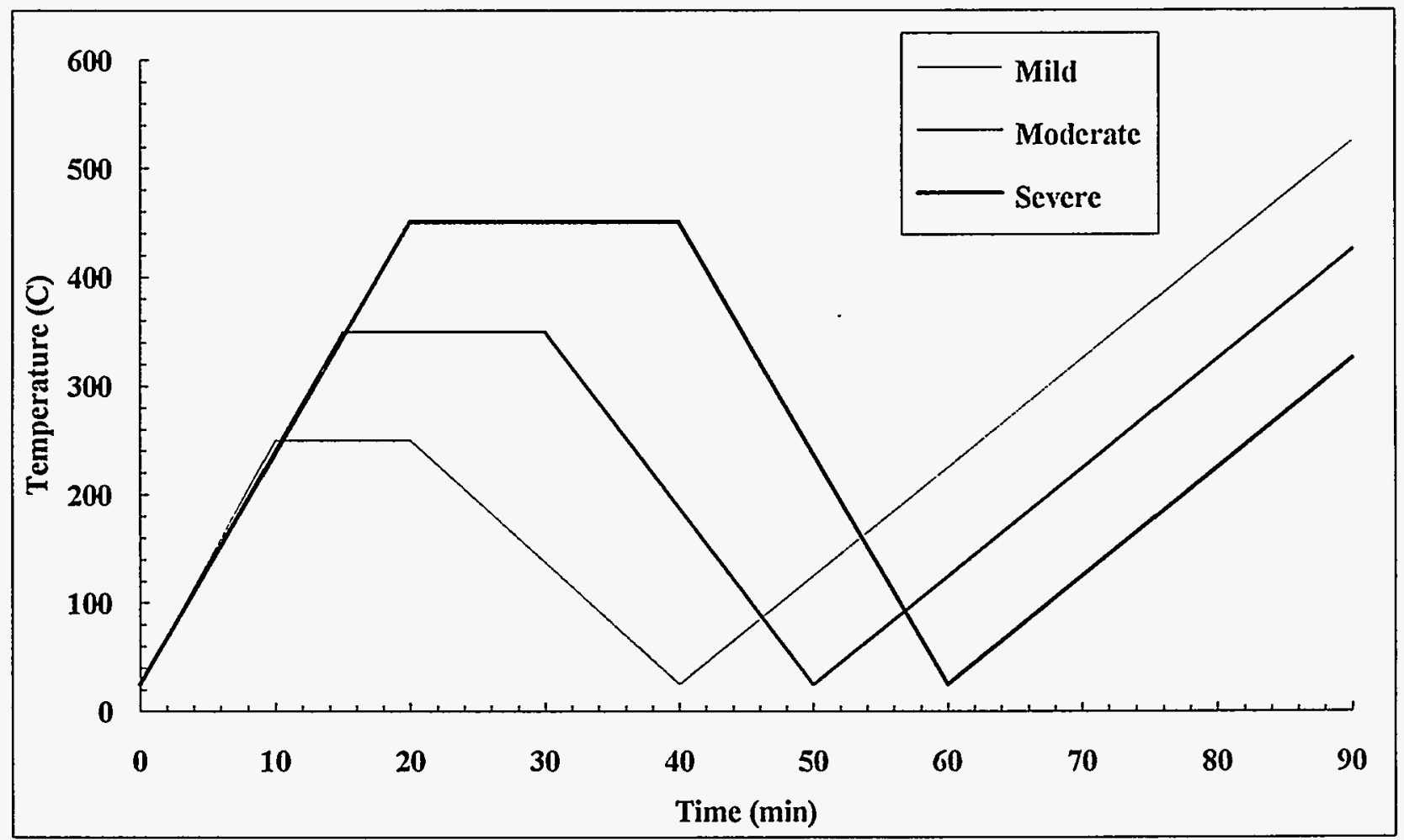

Figure 3 SCETCh temperature exposure profiles 
exposure profile, the initial ramp lasted for approximately 15 minutes, reaching a plateau temperature of $350^{\circ} \mathrm{C}$, which was held for an additional 15 minutes. For the severe exposure profile, the initial ramp lasted for approximately 20 minutes, reaching a plateau temperature of $450^{\circ} \mathrm{C}$, which was held for an additional 20 minutes.

The second phase of each exposure profile consisted of an upward ramp in temperature at a rate of $10^{\circ} \mathrm{C} / \mathrm{min}$ until relay failure was detected. The relay under test would undergo the second phase if and only if it had survived the first phase of the exposure profile. This second phase of the exposure profile was intended to assess the relative margin by which a relay had survived the initial phase of the exposure profile. For example, if the relay failed at a substantially higher temperature than the first phase plateau temperature, then it could be concluded that the relay had survived the first phase with significant margin.

\subsection{Relay Operational Assessments}

During each exposure, the test relay was operated under a 1 amp load for each contact set and was periodically required to actively switch this load. In particular, each 60 second measurement cycle consisted of a period of 50 seconds during which the coil was energized and 10 seconds when the coil was de-energized. The relay's ability to switch the load was monitored to verify operability.

Additional measurements made during each measurement cycle included the relay's coil resistance, contact set resistance, and leakage currents. An electrical schematic of the simulated load and performance monitoring circuit used for each contact set is shown in Figure 4 . The

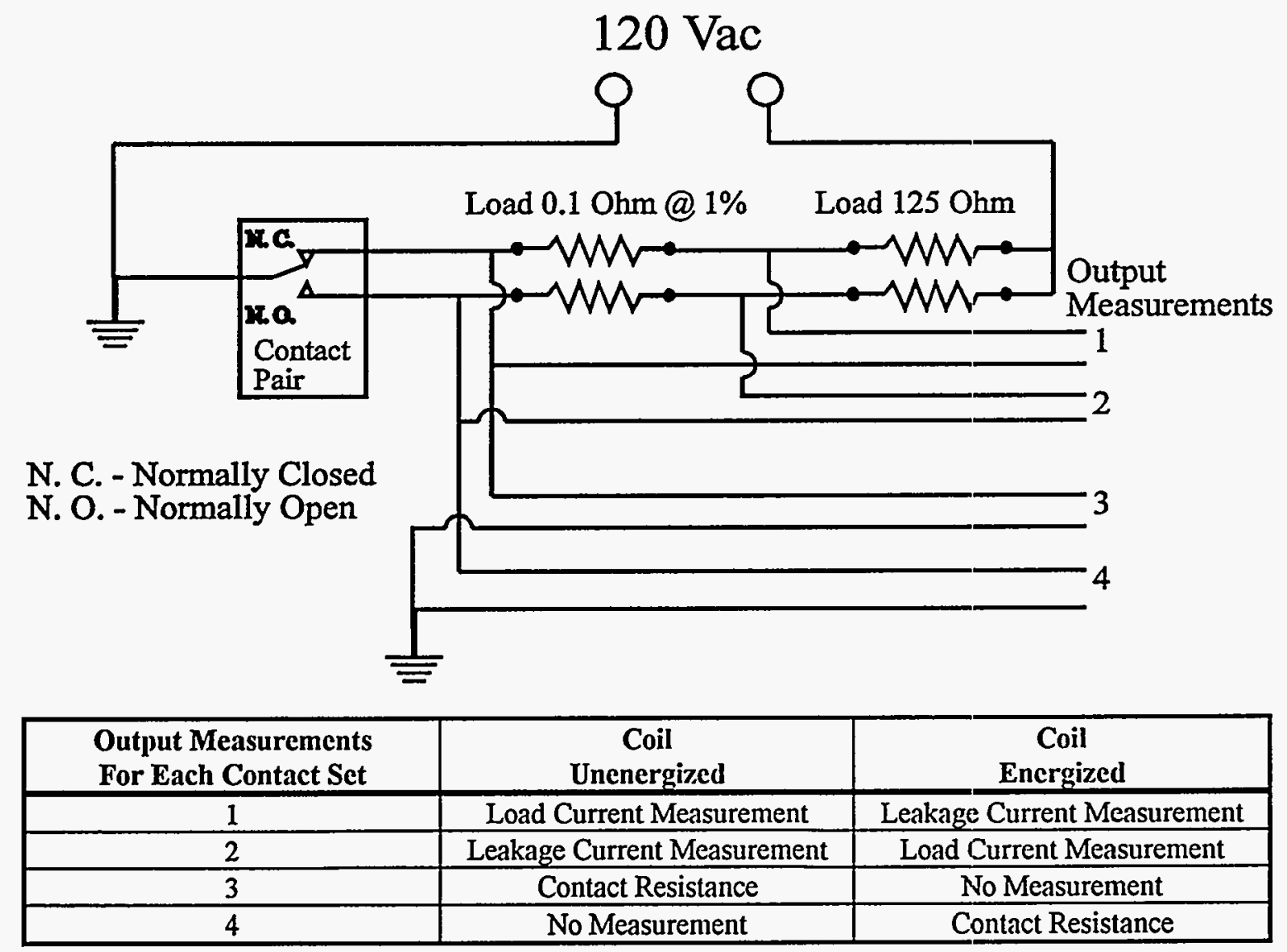

Figure 4 Measurement schematic for each contact set and measurement matrix 
Experimental Arrangement

measurement matrix is also included for clarification.

It was recognized that this mode of operation is not representative of typical in-plant applications. Typically, a relay would be called upon either to hold its current position throughout an event, or to switch positions once and hold the new position. However, the objectives of this test program require that the relative performance of the aged and unaged relays be compared. Hence, it was important to assess both the timing of relay failure during a particular exposure profile as well as the fact of survival or failure. To meet this objective, it was necessary that the relays be operated periodically to assess the continuing operability throughout the exposure. 


\subsection{Experimental Results}

\subsection{Aging}

No anomalies were recorded during the operational cycling of the relays. The coil resistance varied less than $4 \%$ during the cycling for each of the relay types. No coil failures or test equipment anomalies were detected during the thermal aging of the relays.

However, after the thermal aging, it was noted that the armature of the HGA relay was malfunctioning. As the HGA coils were energized, the armatures for each relay easily switched from the normally closed to the normally open position. However, when the coils were deenergized, the armature did not completely return to the normally closed position. It was hypothesized that the thermal aging might have caused the degradation of some unknown lubricant in the pivot. (However, the manufacturer stated that no lubricant was used in the armature.) The manufacturer hypothesized that particulates from outgassing during the thermal aging may prevent the armature from returning to the normally closed position.

Another possibility for the improper operation of the relay was the failure of the return spring. The return action of the armature was controlled by a spring attached to a slotted flange on the armature. A spring from an unaged relay was substituted for the one from the aged relay. With the new spring in place, the relay still did not return to the normally closed position, which indicated that the spring itself was not the cause of the problem. The spring from the aged relay was returned to the original position on the aged relay. The spring was in the original slot position, which was the middle slot on the flange, during operational and thermal aging. As the spring was adjusted to provide the greatest closing force, the first relay still would not return to the normally closed position.

By using low pressure air, the armature from the first aged relay was cleaned to try to remove any particulates that might be hampering the armature movement. After the pressurized air cleaning and the adjustment of the spring's position, the armature returned to the normally closed position when the relay's coil was de-energized. The second relay was also cleaned with pressurized air, and it also had the spring adjusted to provide maximum closing force. Likewise, this relay now performed as required. The position of this spring remained in the slot that provided the greatest closing force so that the remainder of the test program could be completed. The exact cause of this failure was not fully determined during this test program, but it may warrant further investigation. The remaining relays did not experience any problems upon completion of the thermal aging.

\subsection{Thermal Exposure Results}

For each relay type, the first exposure was performed using the unaged samples followed by testing of the aged samples. For each group the first relay sample was subjected to the moderate exposure profile. Based on the result of this exposure, the next sample was subjected to either the mild or severe exposure profile. That is, if the first sample survived the entire first phase of the moderate profile, then the second sample was subjected to the severe profile. Conversely, if the first sample failed during the first phase of the moderate profile, then the second sample was subjected to the mild profile. Certain exceptions to this general test sequence were exercised as described below.

In preparation for testing, relays were energized for approximately 5 minutes prior to the thermal exposure. Failures were determined by either a loss of load-switching capability or the opening of a 1 amp fuse located on the coil input. Upon indication of failure, the experimental control program was allowed to complete another full measurement cycle to verify that a persistent failure had occurred. The power to the SCETCh chamber, the relay load, and the coil power was 
then shut off. The test relay remained in the chamber until the chamber's temperature decreased.

Each relay type was tested in its expected mounting position. The mounting hardware included with each relay was used during the testing. Complete panels were not used, only frame supports as necessary to provide for mounting.

The complete results for all relays tested can be found in Table 2 at the end of this chapter.

Temperature exposure profiles of each relay can be found in Appendix A. The specific details for each relay type are discussed in the following sections.

\subsubsection{Agastat GPI Results}

A previous test program, which evaluated relay functionality during exposures to secondary environments created by a fire, indicated that the Agastat relays were not likely to survive the mild exposure profile[7]. Therefore, all of the Agastat samples were tested in the mild exposure profile.
The Agastat Al relay survived 64 minutes into the mild thermal exposure, failing during the second phase temperature ramp. The temperature at the time of relay failure was $250^{\circ} \mathrm{C}$. Post-test analysis revealed two failure mechanisms. The first failure was detected in the base where two terminals were shorted together because of warpage of the base socket. The second failure discovered was a melted contact carrier that prevented the armature from returning to the normally closed position, as shown in Figure 5. During the previous test program [7] an Agastat GPI relay displayed a similar contact carrier failure at a temperature of approximately $210^{\circ} \mathrm{C}$. (Note that this earlier program utilized a slowly increasing temperature profile until failure was detected.)

The second aged Agastat relay, A2, survived approximately 24 minutes, failing during the early stages of the cool-down period. The peak exposure temperature was $241^{\circ} \mathrm{C}$, and the temperature at the time of failure was $210^{\circ} \mathrm{C}$.

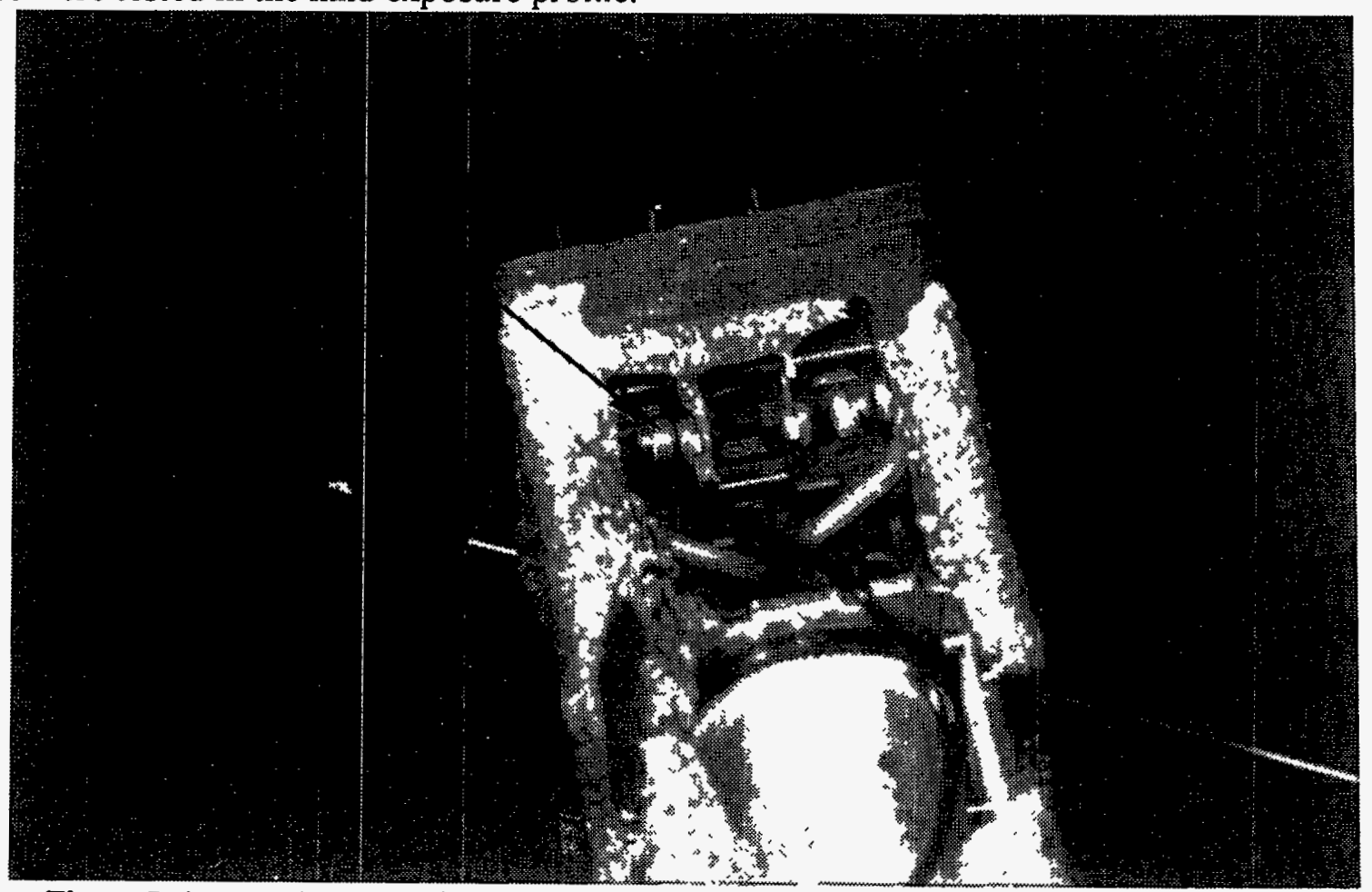

Figure 5 Agastat A1 relay with normally-open contact stuck because of a melted contact carrier 
Post-test analysis revealed that a capacitor in the coil rectification circuit had a visible burnt crack at the top portion of the device. A continuity check of the coil rectification circuit indicated an open circuit.

The unaged Agastat relays, A3 and A4, failed approximately 11 and 14 minutes into the exposure, respectively. In each case, the failures occurred early in the plateau period. The temperatures at the time of failure were $206^{\circ} \mathrm{C}$ and $221^{\circ} \mathrm{C}$, respectively. The failure mode was similar to that of relay A2, namely, an open circuit in the coil rectification circuits. The capacitors did not display visible cracking as in A2.

\section{Agastat unaged relays $\mathrm{A} 5$ and $\mathrm{A} 6$ failed} approximately 11 and 12 minutes into the exposure, respectively. In each case, the failures occurred early in the plateau period. The temperatures at the time of failure were $215^{\circ} \mathrm{C}$ in both cases. In each case the failures were traced to the bases. Post-test analysis revealed that a short had occurred between two terminal sockets in each base. The short caused each relay to fail.

Contact resistance measurements for all Agastat relays were typically below $70 \mathrm{~m} \Omega$. The highest recorded contact resistance for any relay was $86 \mathrm{~m} \Omega$. Load currents remained stable until failures were observed. Open contact leakage currents were generally erratic and provided limited information.

Failures for the Agastat relays were attributed to three failure modes: shorting of the base, failure of the built in rectification circuit, or warpage of the contact carriers. The manufacturer recommended operating-temperature range for this relay is $0{ }^{\circ} \mathrm{C}$ to $60^{\circ} \mathrm{C}$. All the failures observed occurred at temperatures in excess of $200^{\circ} \mathrm{C}$.

The aged samples survived longer in the test environment than the unaged samples, which suggests that the aging protocol enhanced the relay's ruggedness. It is suspected that the aging process annealed the coil rectification circuit components, increasing their tolerance to thermal exposures.

\subsubsection{General Electric HMA Results}

The first aged relay, B1, was tested in the moderate profile and failed at the end of the cooldown portion of the exposure. The peak exposure temperature was $352^{\circ} \mathrm{C}$, and the temperature at failure was $129^{\circ} \mathrm{C}$. The failure observed was associated with an armature actuation failure. Post-test analysis revealed that a substance, apparently released from the coil's spool, accumulated on the top of the coil and prevented the armature from actuating.

The second aged relay, B2, was tested in the severe profile and failed early in the plateau period. The temperature at the time of failure was $447^{\circ} \mathrm{C}$. The mode of failure was identical to that of relay $\mathrm{B} 1$.

The first unaged relay, B3, was tested in the moderate profile and failed midway through the plateau period. The temperature at the time of failure was $348^{\circ} \mathrm{C}$. The mode of failure was again associated with an armature failure.

However, in this case a closer inspection revealed that the armature had fused to the relay's housing. The point of the fusing is shown in Figure 6. The armature arm was separated from the housing when slight pressure was applied. However, it still did not actuate freely because of warpage of the relay's housing.

The second unaged relay, B4, was tested in the mild profile. The relay survived the entire first phase of the exposure and failed during the second phase. The temperature at the time of failure was approximately $400^{\circ} \mathrm{C}$. The mode of failure was identical to that observed for relay B1.

It was evident from these results that the aged specimens performed slightly better than the unaged specimens. Three of the four failures, including both of the aged and one of the unaged samples, were attributed to the accumulation of 


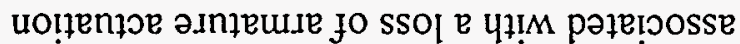

SEM әIn!IEJ әчI 'p

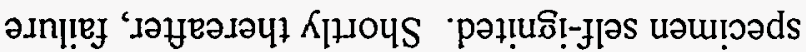

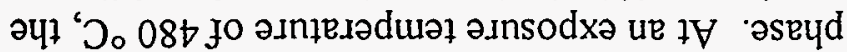

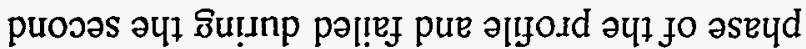

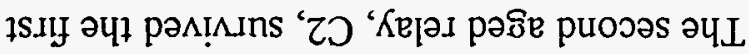

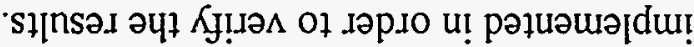

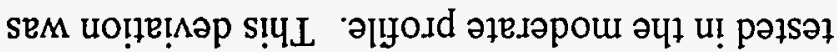

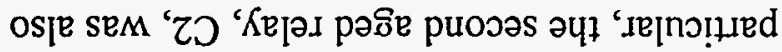

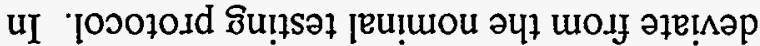

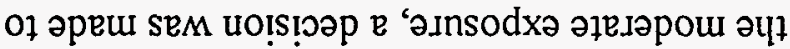

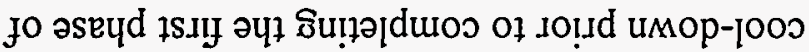

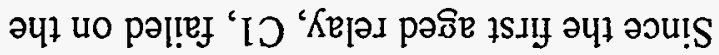

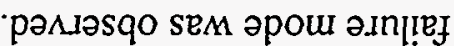

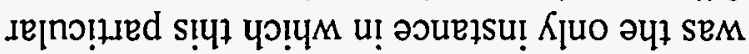

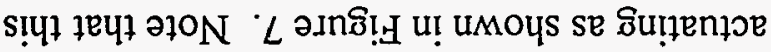

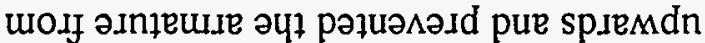

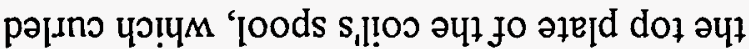

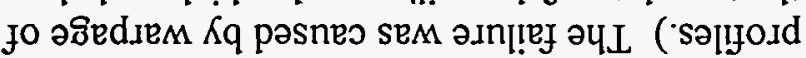

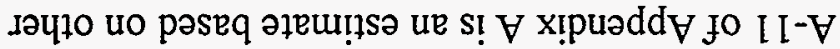

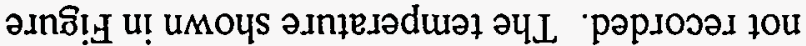

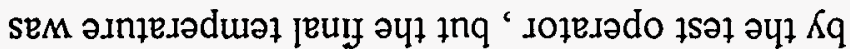

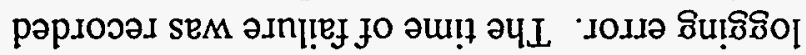

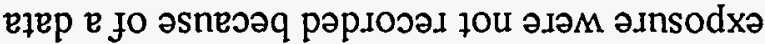

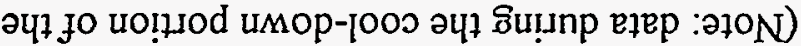

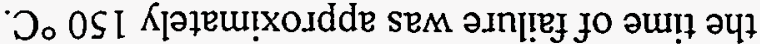

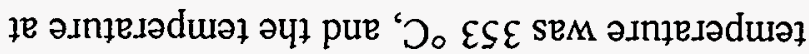

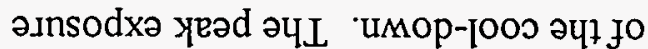

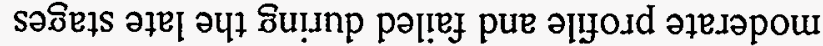

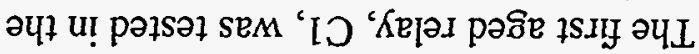

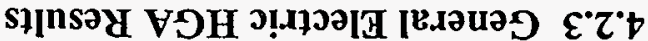

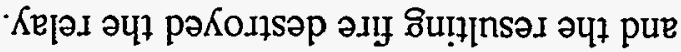

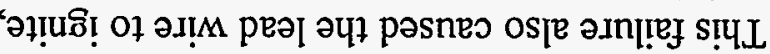

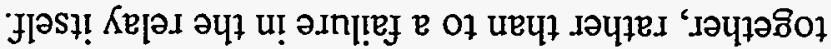

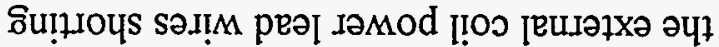

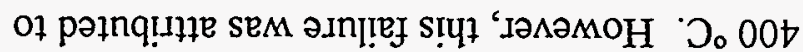

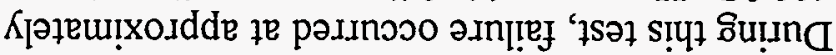

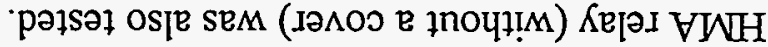

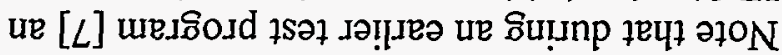

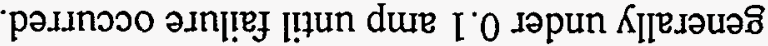

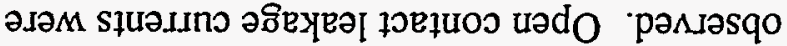

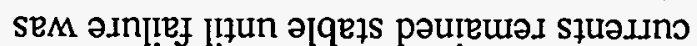

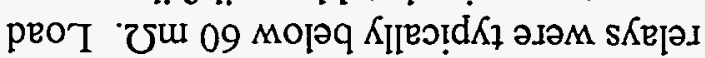
$\forall$ WWH

8uisnoy

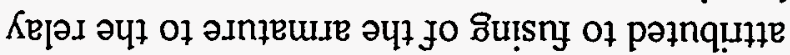

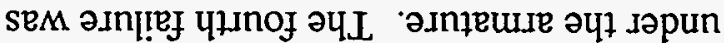

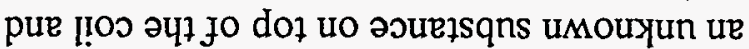

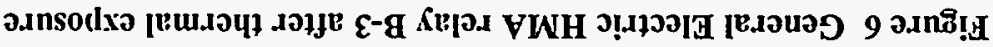

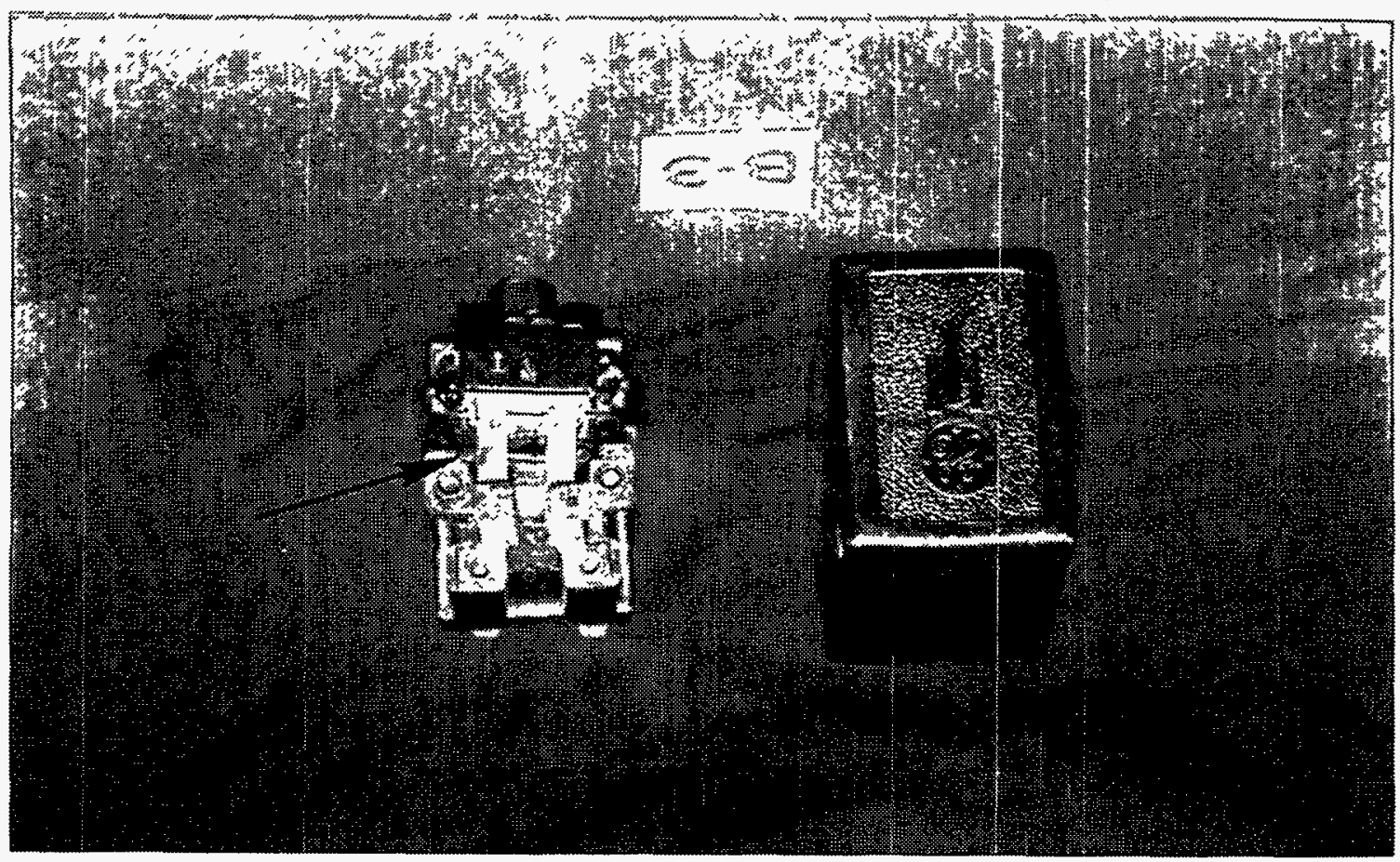




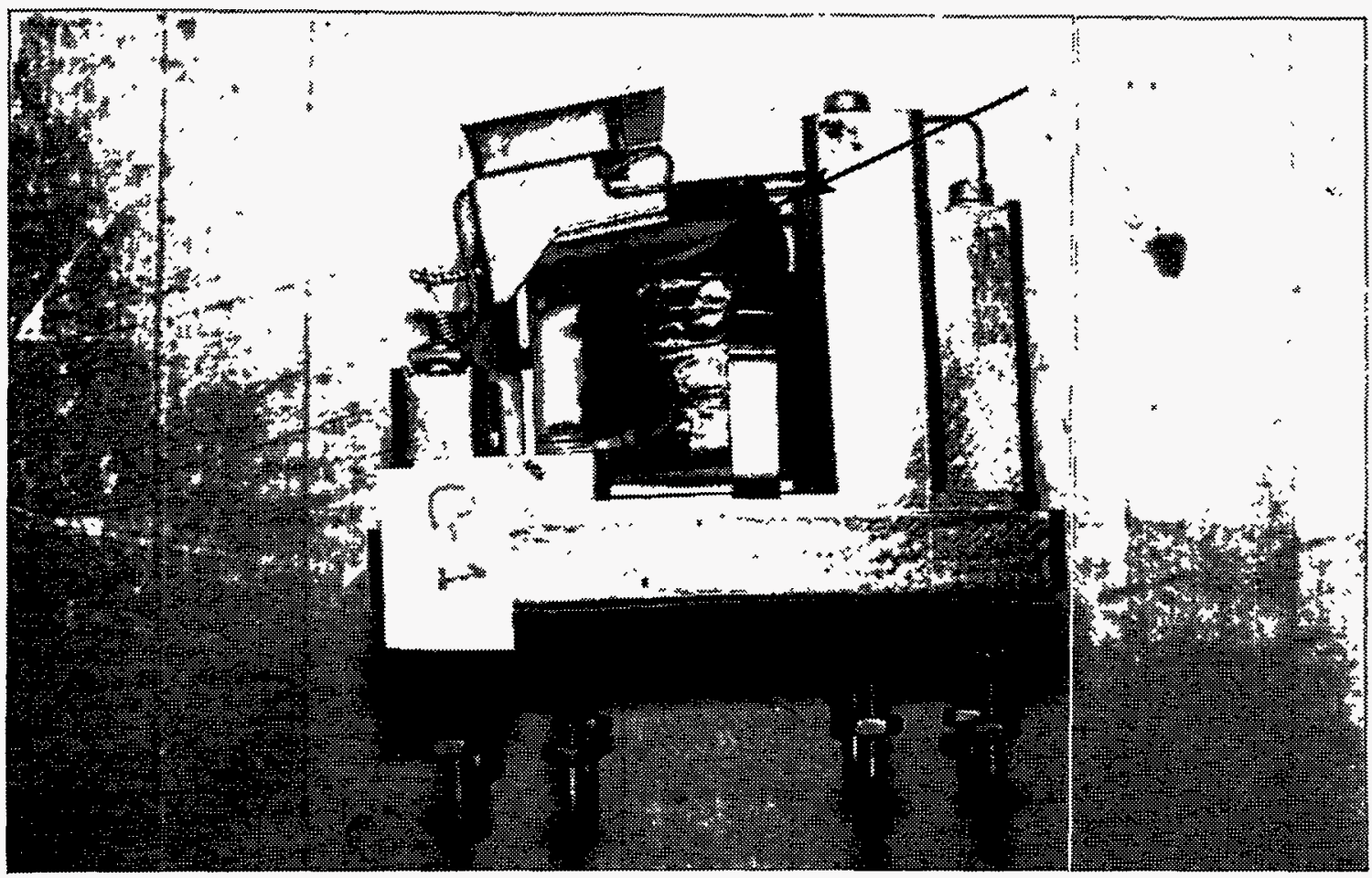

Figure 7 General Electric HGA relay C-1 failure of the spool's top plate

capability. Inspection of the charred remains of the coil and the armature showed that the armature and coil had become fused together because of the accumulation of an unknown substance beneath the armature. (Recall that similar behavior was noted in three of the four HMA relays tested.)

The first unaged relay, C3, was tested in the moderate profile and survived the entire first phase of the exposure. Failure was noted during the second phase at a temperature of $488^{\circ} \mathrm{C}$. Failure was attributed to the accumulation of an unknown substance underneath the armature on top of the coil's spool. This substance prevented the armature from actuating. (Note that similar failure mechanisms occurred for the two different coil designs, the GE HMA and GE HGA.)

(The C3 relay was the first GE relay tested from among all relays. The control program used in this test was identical to that used for the Agastat tests. Because of the variation between the actual and the intended profile, the control program was modified to compensate for this variation. The variation can be observed by comparing Figure A-13 to A-11 or A-12. The difference was determined to be caused by the controlling thermocouple's location relative to the chamber and the test specimen. The remaining relays were tested using the new control program, which produced exposure profiles that were very similar to the desired exposure profiles.)

The second unaged relay, $\mathrm{C} 4$, was tested in the severe profile and failed at the end of the plateau period. The temperature at the time of failure was $453^{\circ} \mathrm{C}$. The failure mode was identical to that of relay $\mathrm{C} 3$; namely, an accumulation of an unknown substance underneath the armature prevented the armature from actuating. This substance can be seen in Figure 8.

Based on the time to failure and final temperature, the two unaged relays appear to have performed slightly better than the aged relays, given these temperature profiles. However, the difference in 


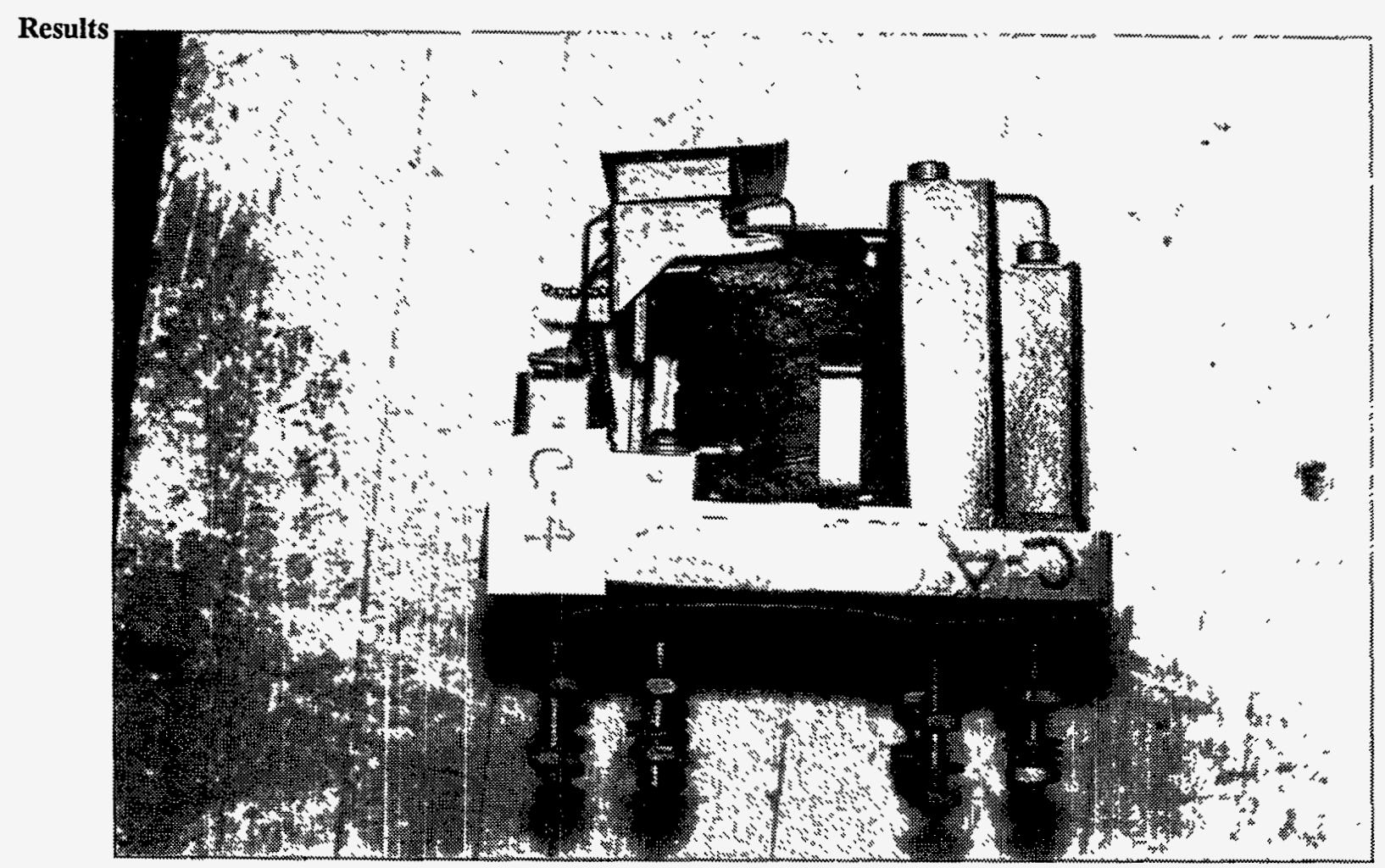

Figure 8 General Electric HGA relay $\mathrm{C}-4$ failure of the armature because of blockage

the results for the aged and unaged relays is not significant.

Contact resistance measurements for all GE HGA relays were typically below $60 \mathrm{~m} \Omega$. Load currents remained stable until failure was observed. Open contact leakage currents were generally under $0.1 \mathrm{amp}$ until failure occurred.

\subsubsection{General Electric HFA Results}

The first aged relay, D1, was tested in the moderate profile and failed early in the cool-down period. The peak exposure temperature was $359^{\circ} \mathrm{C}$, and the temperature at failure was $349^{\circ} \mathrm{C}$. The failure of two of the six contacts pairs was noted in load current measurements. Upon inspection, it was noted that the armature was warped or bowed. This warpage was severe enough to prevent the closure of two of the six contact pairs. However, the coil remained functional during post-test analysis.

The second aged relay, D2, was tested in the mild profile. The relay survived the first phase of the exposure and failed during the second phase at a temperature of $485^{\circ} \mathrm{C}$. The failure was attributed to severe deformation of the relay body. The relay's components were misaligned, and the armature movement was not free enough to complete contact (make or break).

The relay D3 was tested in the moderate profile and failed midway through the cool-down. The peak exposure temperature was $348^{\circ} \mathrm{C}$, and the temperature at failure was $298^{\circ} \mathrm{C}$. The mode of failure was similar to D1.

Relay D4 was tested in the severe profile and failed midway through the plateau. At an exposure temperature of approximately $450^{\circ} \mathrm{C}$, the specimen self-ignited. Shortly thereafter failure of the relay was observed. The ensuing fire destroyed the relay.

The final relay tested, D5, was tested in the mild environment. The relay survived the first phase of the exposure and failed during the second phase at a temperature of $440^{\circ} \mathrm{C}$. The test data indicated that the coil did not actuate when power was applied. However, post-test analysis did not find any problems with the coil or the armature. The 
armature was slightly misaligned and slightly warped, but the contacts were all making contact. The exact cause of the failure was not evident. It was noted that when the coil was energized the relay hummed and chattered loudly. On one subsequent energization, the armature failed to actuate. Hence it was concluded that this relay was subject to an intermittent failure.

From these results, it can be seen that the aged and unaged relays behaved quite similarly under the given test conditions. The results of the aged and unaged HFA relays suggest that the relays will most likely survive in a fire with an exposure similar to the mild profile. Survival in fires corresponding to the moderate and severe profiles is doubtful.
Contact resistance measurements for all GE HFA relays were typically below $90 \mathrm{~m} \Omega$. Load currents remained stable until failure was observed. Open contact leakage currents were erratic but generally under 0.2 amp until failure occurred.
All of the relays tested showed signs of deformation of the relay body. Many of the outer shells were cracked. Most of the relay bodies were also bowed or warped, as can be seen in Figure 9. The deformation of the relay body was evident in each of the GE HFA relays, with some more severe than others. The failures for four of the GE HFA relays were attributed to warpage of the armature.

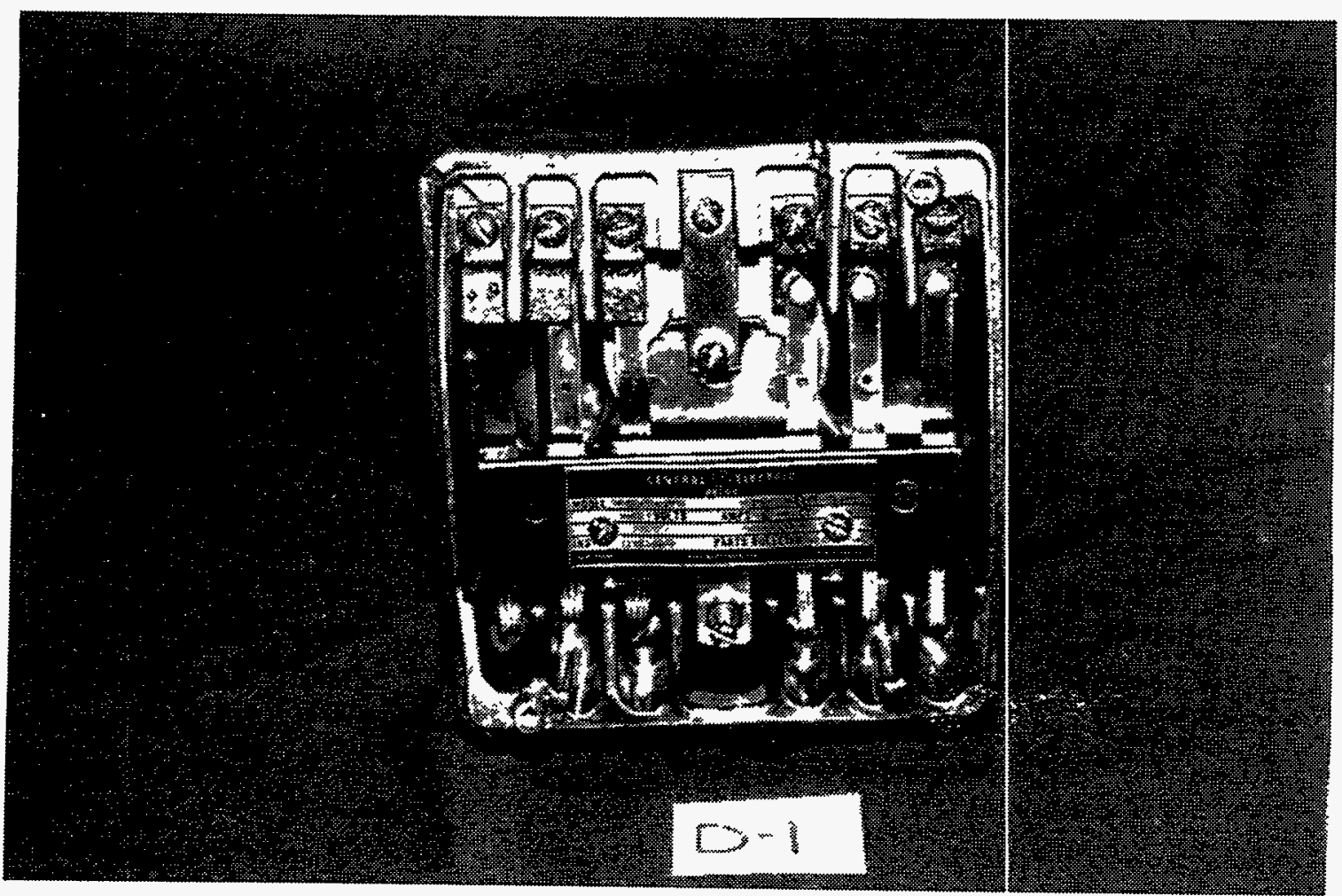

Figure 9 General Electric HFA relay D-1 after thermal exposure 
Results

Table 2 Overall relay test results

\begin{tabular}{|c|c|c|c|c|c|c|c|c|}
\hline Relay \# & $\begin{array}{c}\text { Aged } \\
\text { or } \\
\text { Unaged }\end{array}$ & Profile & $\begin{array}{l}\text { Test } \\
\text { Order }\end{array}$ & $\begin{array}{l}\text { Survived } \\
\text { 1st phase }\end{array}$ & $\begin{array}{l}\text { Time of } \\
\text { Failure } \\
\text { (hh:mm) }\end{array}$ & $\begin{array}{c}\text { Peak } \\
\text { Temperature } \\
\left({ }^{\circ} \mathrm{C}\right)\end{array}$ & $\begin{array}{c}\text { Temperature } \\
\text { at Failure } \\
\left({ }^{\circ} \mathrm{C}\right)\end{array}$ & $\begin{array}{l}\text { Failure } \\
\text { Mode }\end{array}$ \\
\hline $\begin{array}{c}\text { Agastat } \\
\text { A1 }\end{array}$ & Aged & Mild & 5 & Yes & $01: 04$ & 250.4 & 250.4 & $\begin{array}{c}\text { Stuck contact \& } \\
\text { Base shorted }\end{array}$ \\
\hline $\begin{array}{c}\text { Agastat } \\
\text { A2 }\end{array}$ & Aged & Mild & 6 & No & $00: 24$ & 241.1 & 209.7 & $\begin{array}{l}\text { Rectification circuit } \\
\text { failure }\end{array}$ \\
\hline $\begin{array}{c}\text { Agastat } \\
\mathrm{A} 3\end{array}$ & Unaged & Mild & 1 & No & $00: 11$ & 206.4 & 206.4 & $\begin{array}{l}\text { Rectification circuit } \\
\text { failure }\end{array}$ \\
\hline $\begin{array}{c}\text { Agastat } \\
\text { A4 }\end{array}$ & Unaged & Mild & 2 & No & $00: 13$ & 220.7 & 220.7 & $\begin{array}{l}\text { Rectification circuit } \\
\text { failure }\end{array}$ \\
\hline $\begin{array}{l}\text { Agastat } \\
\text { A5 }\end{array}$ & Unaged & Mild & 3 & No & $00: 11$ & 214.4 & 214.4 & Base shorted \\
\hline $\begin{array}{c}\text { Agastat } \\
\text { A6 }\end{array}$ & Unaged & Mild & 4 & No & $00: 12$ & 214.5 & 214.5 & Base shorted \\
\hline $\begin{array}{l}\text { GE HMA } \\
\text { B1 }\end{array}$ & Aged & Moderate & 13 & Yes & $00: 49$ & 352.4 & 129.1 & $\begin{array}{l}\text { Armature failed to } \\
\text { actuate }\end{array}$ \\
\hline $\begin{array}{l}\text { GE HMA } \\
\text { B2 }\end{array}$ & Aged & Severe & 14 & No & $00: 23$ & 446.9 & 446.9 & $\begin{array}{c}\text { Armature failed to } \\
\text { actuate }\end{array}$ \\
\hline $\begin{array}{c}\text { GE HMA } \\
\text { B3 }\end{array}$ & Unaged & Moderate & 11 & No & $00: 20$ & 348.2 & 348.2 & $\begin{array}{l}\text { Armature fused to side } \\
\text { of relay }\end{array}$ \\
\hline $\begin{array}{c}\text { GE HMA } \\
\text { B4 }\end{array}$ & Unaged & Mild & 12 & Yes & $01: 19$ & 402.9 & 402.9 & $\begin{array}{c}\text { Armature failed to } \\
\text { actuate }\end{array}$ \\
\hline $\begin{array}{c}\text { GE HGA } \\
\mathrm{Cl}\end{array}$ & Aged & Moderate & 9 & No & $00: 43^{*}$ & $352.6^{*}$ & $150^{*}$ & $\begin{array}{l}\text { Armature blocked by } \\
\text { warped top coil plate }\end{array}$ \\
\hline $\begin{array}{c}\text { GE HGA } \\
\mathrm{C} 2 \\
\end{array}$ & Aged & Moderate & 10 & Yes & $01: 38$ & $745.6^{* *}$ & $551.9^{* *}$ & $\begin{array}{l}\text { Armature blocked, } \\
\text { relay destroyed }\end{array}$ \\
\hline $\begin{array}{c}\text { GE HGA } \\
\mathrm{C} 3\end{array}$ & Unaged & Moderate & 7 & Yes & $01: 40$ & 487.7 & 487.7 & $\begin{array}{c}\text { Armature failed to } \\
\text { actuate }\end{array}$ \\
\hline $\begin{array}{c}\text { GE HGA } \\
\mathrm{C} 4 \\
\end{array}$ & Unaged & Severe & 8 & No & $00: 36$ & 453.4 & 453.2 & $\begin{array}{l}\text { Armature failed to } \\
\text { actuate }\end{array}$ \\
\hline $\begin{array}{c}\text { GE HFA } \\
\text { D1 }\end{array}$ & Aged & Moderate & 18 & No & $00: 31$ & 358.9 & 348.7 & Armature warped \\
\hline $\begin{array}{l}\text { GE HFA } \\
\text { D2 }\end{array}$ & Aged & Mild & 19 & Yes & $01: 26$ & 484.7 & 484.7 & Armature warped \\
\hline $\begin{array}{c}\text { GE HFA } \\
\text { D3 } \\
\end{array}$ & Unaged & Moderate & 15 & No & $00: 34$ & 348.2 & 297.5 & Armature warped \\
\hline $\begin{array}{c}\text { GE HFA } \\
\text { D4 }\end{array}$ & Unaged & Severe & 17 & No & $00: 34$ & $563.8^{* *}$ & $563.8^{* *}$ & $\begin{array}{c}\text { Completely destroyed } \\
\text { by fire }\end{array}$ \\
\hline $\begin{array}{l}\text { GE HFA } \\
\text { D5 }\end{array}$ & Unaged & Mild & 16 & Yes & $01: 23$ & 440.0 & 440.4 & Intermittent Failure \\
\hline
\end{tabular}

* Exact time and temperature of failure not recorded because of a data logging error. Failure occurred during cool-down ramp at the listed estimated time and temperature.

** Temperatures are higher than expected because the relay's materials ignited and bumed. 


\subsection{Conclusions}

This test program assessed the impact of operational and thermal aging on the thermal vulnerability of relays. The relays evaluated were Agastat GPI, General Electric HMA, General Electric HGA, and General Electric HFA. At least two relays of each type were tested in an unaged condition and at least two relays of each type were artificially aged prior to testing. The aged samples were operationally aged by cycling the relay under rated load for 2000 operations. These relays were then subjected to thermal aging for 60 days at a temperature of $110^{\circ} \mathrm{C}$ with their coils energized.

Thermal exposure testing was conducted in SNL's Severe Combined Environments Test Chamber (SCETCh). Three exposure profiles were developed for this test program. These profiles were representative of generic mild, moderate or severe thermal exposures, respectively.

The Agastat GPI relay results indicated that most relays would not survive in a mild exposure $\left(250^{\circ} \mathrm{C}\right)$ environment . However, the aged samples survived longer than the unaged samples. Failures were generally traced to the coil rectification circuit. However, failures in the base socket were also encountered.

The GE HMA and GE HGA failures were generally attributed to failure of the armature to actuate properly. For both relay types, most of the failures were attributed to an accumulated substance that formed on the top plate of the coil's spool just below the armature. One GE HMA relay failure was attributed to the armature becoming fused to the relay's housing. One GE HGA relay failure was caused by the armature failing to actuate because the top plate of the coil had curled upwards, preventing movement of the armature. Aging was not a significant factor in any of the failures.

The GE HFA relay failures were generally caused by warpage of the armature arm. This warpage prevented certain contacts from fully engaging. One GE HFA displayed an intermittent coil actuation failure. All of the relays tested exhibited severe distortion of the relay body. Aging was not a significant factor in the failures.

In general, it can be concluded that the effect of aging on the fire vulnerability of relays appears to be insignificant. Depending on the relay type, the effect of exposure to even mild temperature excursions $\left(>200^{\circ} \mathrm{C}\right)$ may affect relay integrity independent of the relay's age.

It was also noted that a relay may function properly at a high temperature for a period of time and subsequently fail upon cooling. This was observed in four of the relays tested in this program (one sample from each relay type). The most common failure mode observed was failure of the armatureto actuate on command because of blockage or warpage. 


\subsection{References}

1. Lowry, W. and Vigil, R. A., "Prioritization of Reactor Control Components Susceptible to Fire Damage as a Consequence of Aging," NUREG/CR-6103, SAND937107, Science \& Engineering Associates, Inc. for Sandia National Laboratories, January 1994.

2. Toman, G. J., Bacanskas, V. P., Shook, T. A., and Ladlow, C. C., "An Aging Assessment of Relays and Circuit Breakers and System Interactions," Franklin Research Center, NUREG/CR-4715 (BNL-NUREG52017), June 1987.

3. Lambright, J. A., Nowlen, S. P., Nicolette, V. F., and Bohn, M. P., "Fire Risk Scoping Study: Investigation of Nuclear Power Plant Fire Risk, Including Previously Unaddressed Issues, "NUREG/CR-5088, SAND88-0177, Sandia National Laboratories, January 1989.

4. Cline, D. D., von Riesemann, W. A., Chavez, J. M., "Investigation of Twenty-Foot Separation Distance as a Fire Protection Method as Specified in 10 CFR 50, Appendix R," NUREG/CR-3192, SAND83-0306, Sandia National Laboratories, October 1983.
5. Nowlen, S. P., "Enclosure Environment Characterization Testing for the Base Line Validation of Computer Fire Simulation Codes," NUREG/CR-4681, Sandia National Laboratories, March 1987.

6. Chavez, J. M., Nowlen, S. P. "An Experimental Investigation of Internally Ignited Fires in Nuclear Power Plant Control Cabinets: Part 1: Cabinet Effects Test, Part 2: Room Effects Tests," NUREG/CR-4527/V1 \& V2, SAND860336, Volumes $1 \& 2$, Sandia National Laboratories, April 1987 \& November 1988.

7. Jacobus, M. J., "Screening Tests of Representative Nuclear Power Plant Components Exposed to Secondary Environments Created by Fires," NUREG/CR-4596, SAND86-0394, June 1986. 


\section{Appendix A SCETCh Temperature Exposure Plots for All Relays Tested}

In this appendix, the temperature exposure profiles are shown for each relay tested. Each figure contains the desired profile (mild, moderate, or severe) and the actual temperature profile. Note that the relays were tested in the order listed in Table 2 in the report. The thermal exposures were perfomed in Sandia National Laboratories' Severe Combined Environments Test Chamber. 



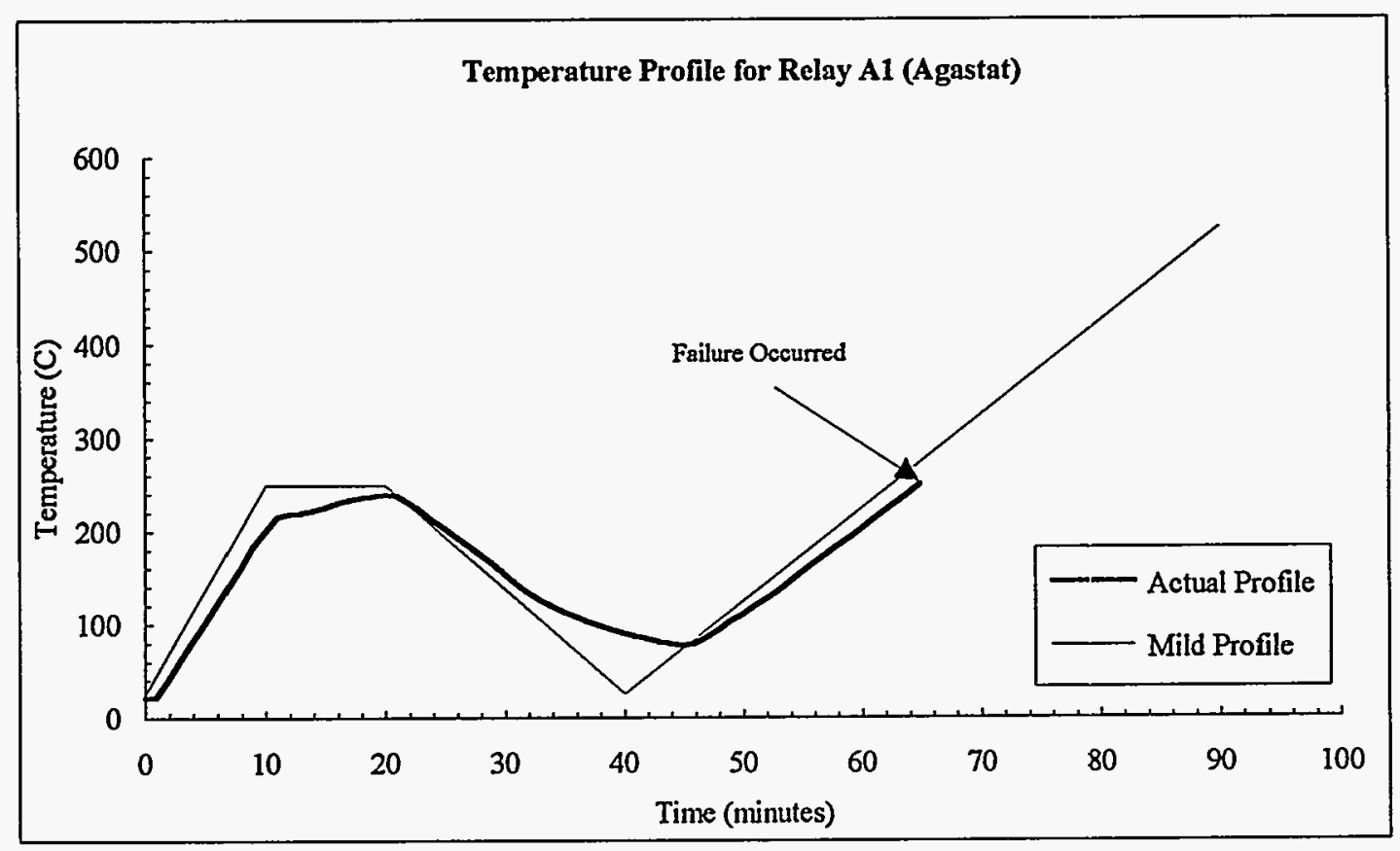

Figure A-1 SCETCh temperature exposure for relay A1

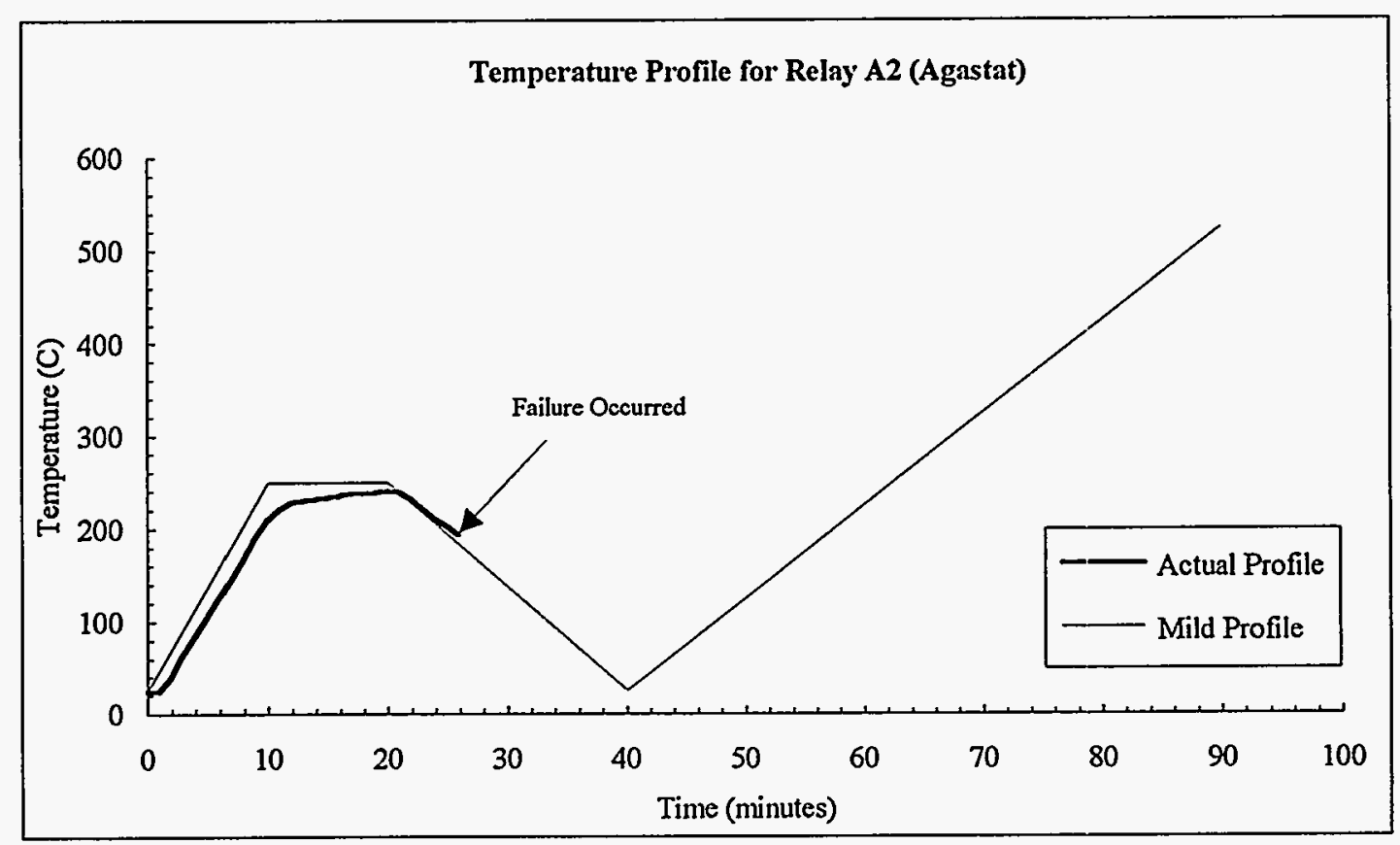

Figure A-2 SCETCh temperature exposure for relay A2 


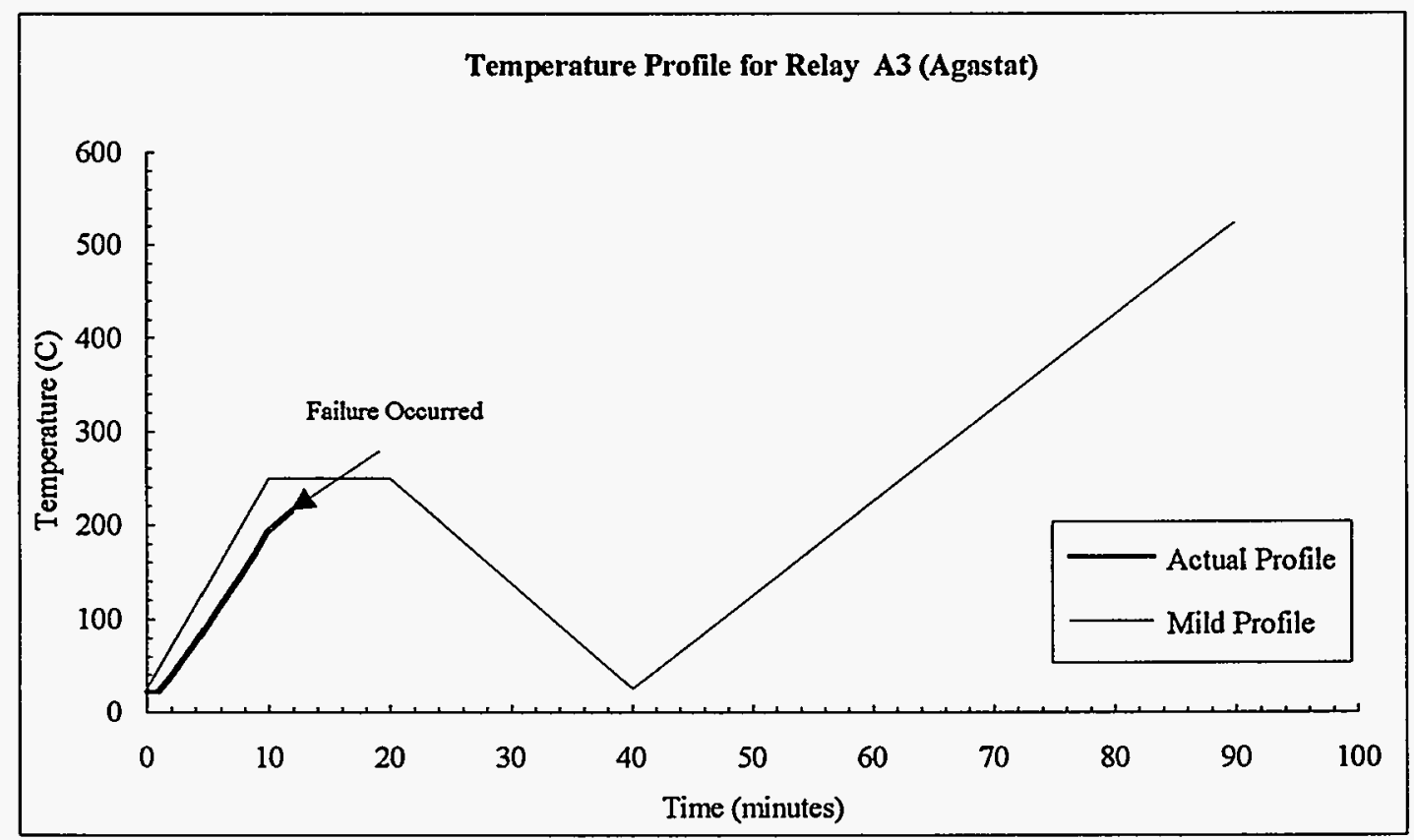

Figure A-3 SCETCh temperature exposure for relay A3

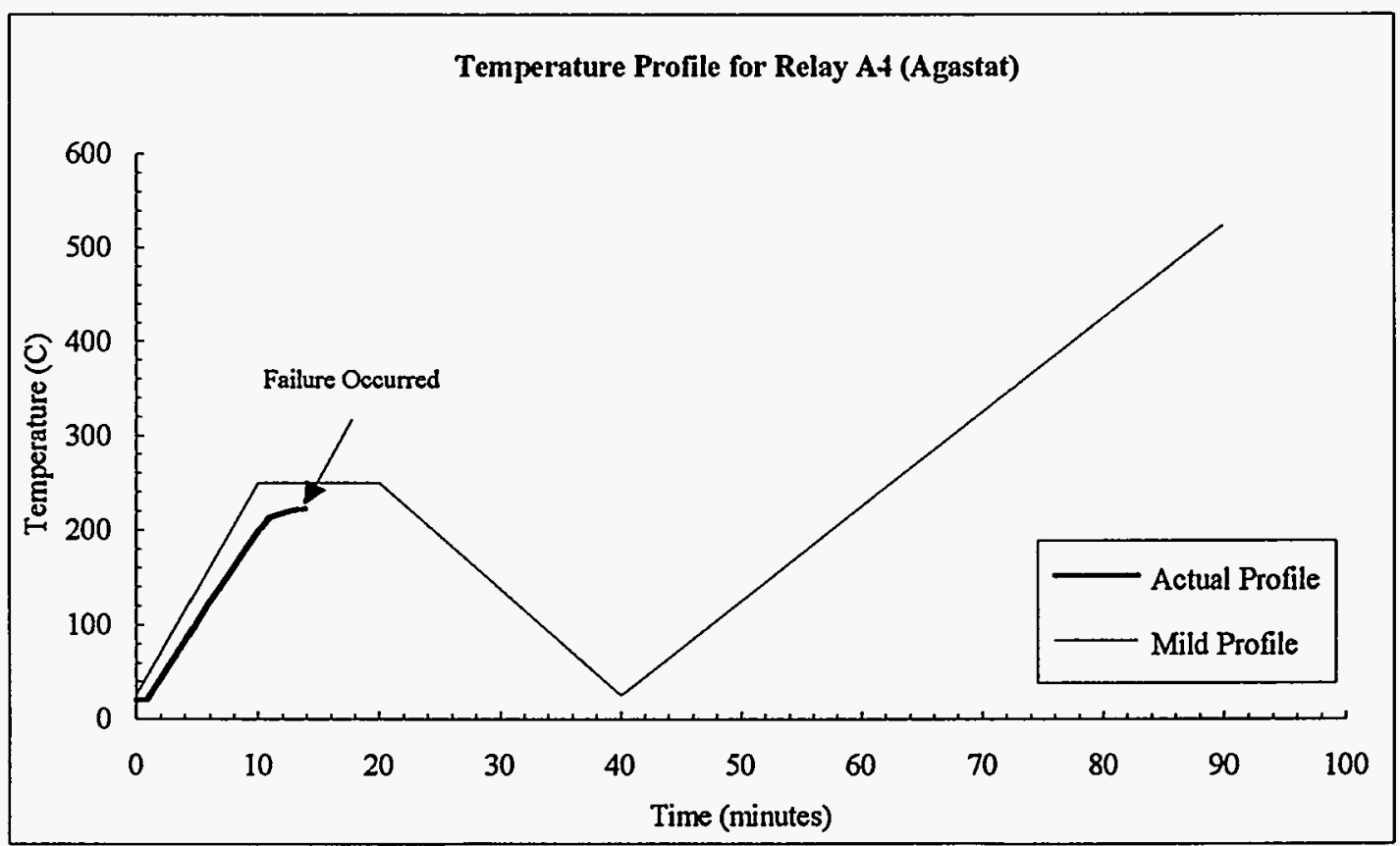

Figure A-4 SCETCh temperature exposure for relay A4 


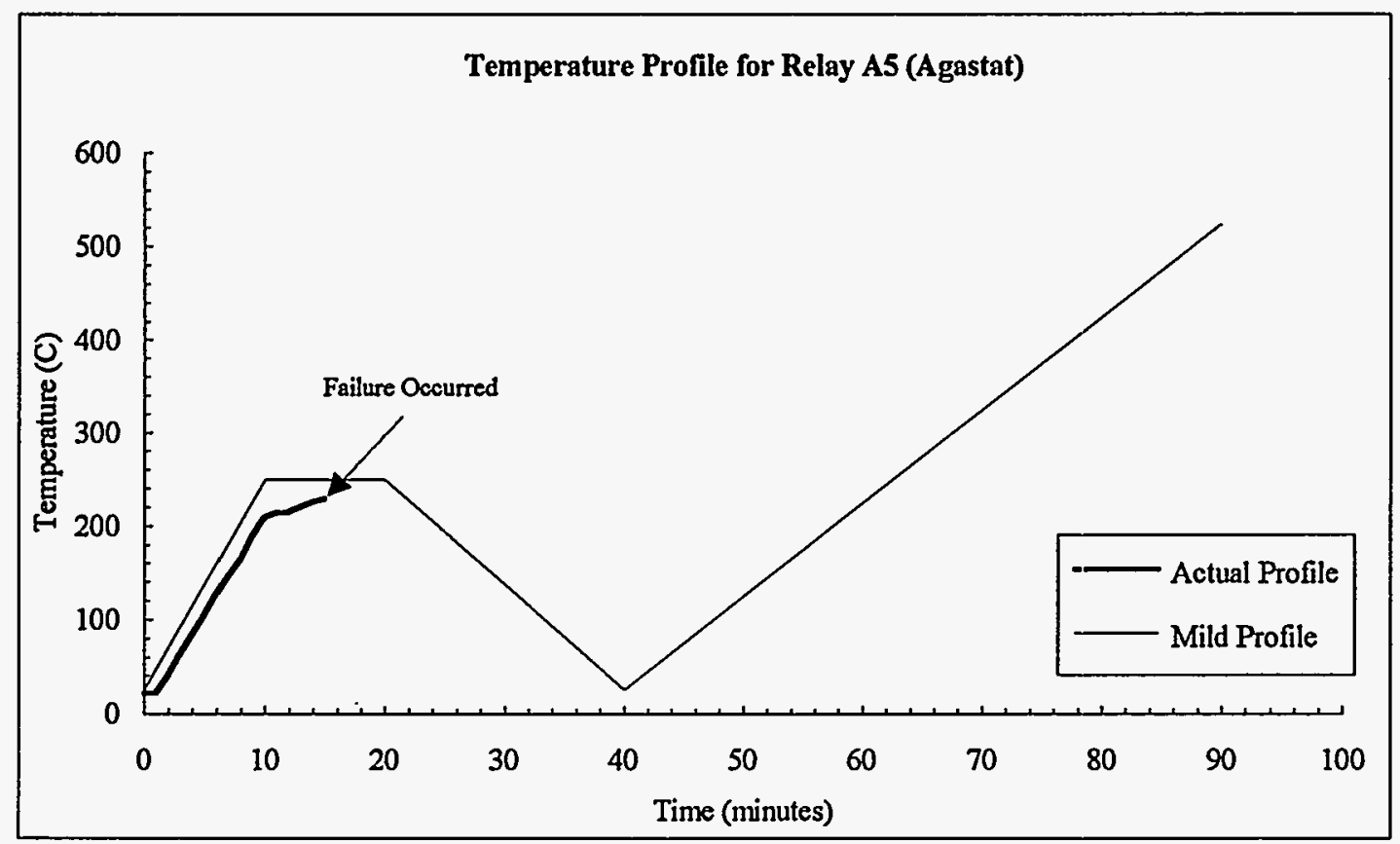

Figure A-5 SCETCh temperature exposure for relay A5

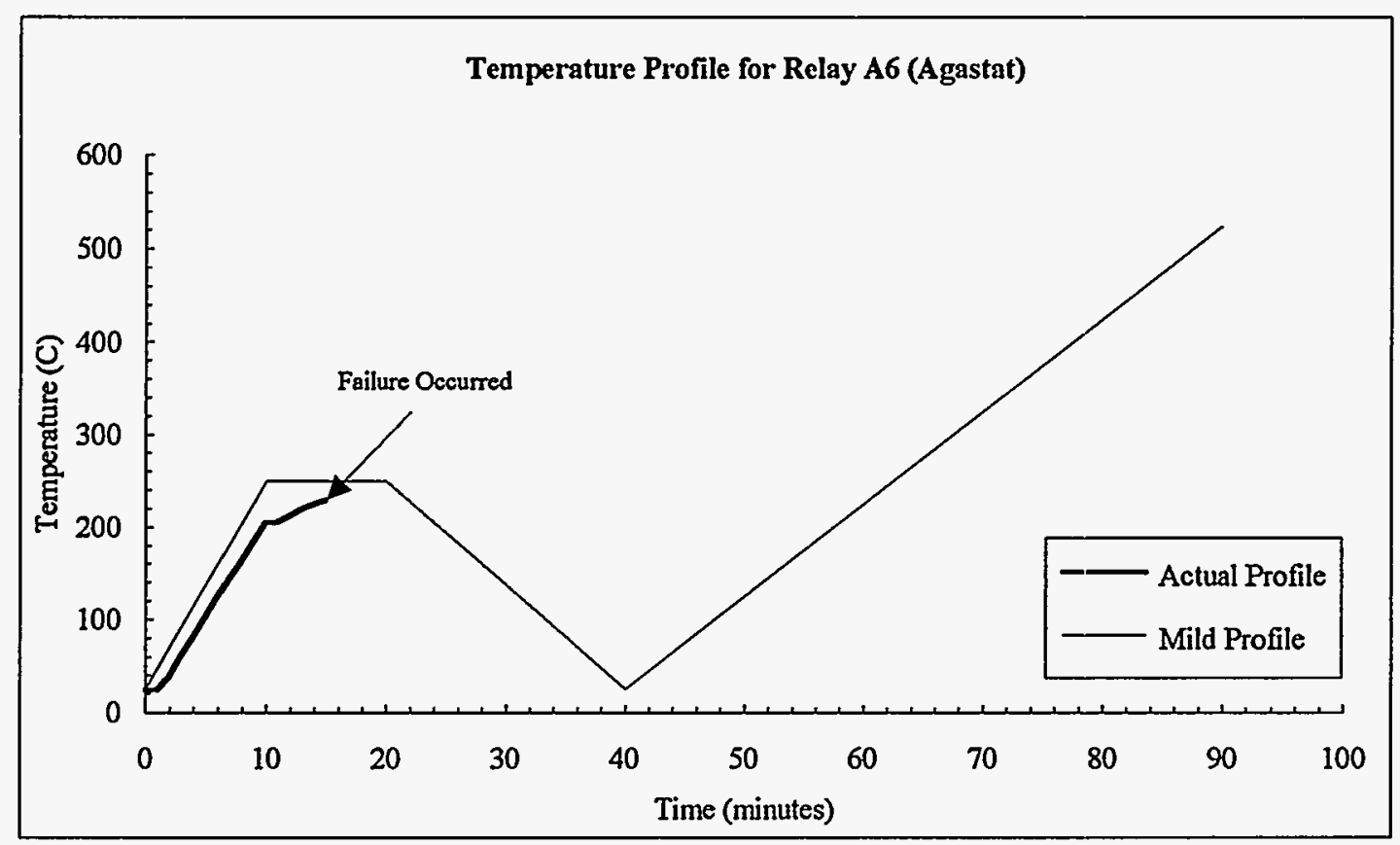

Figure A-6 SCETCh temperature exposure for relay A6 


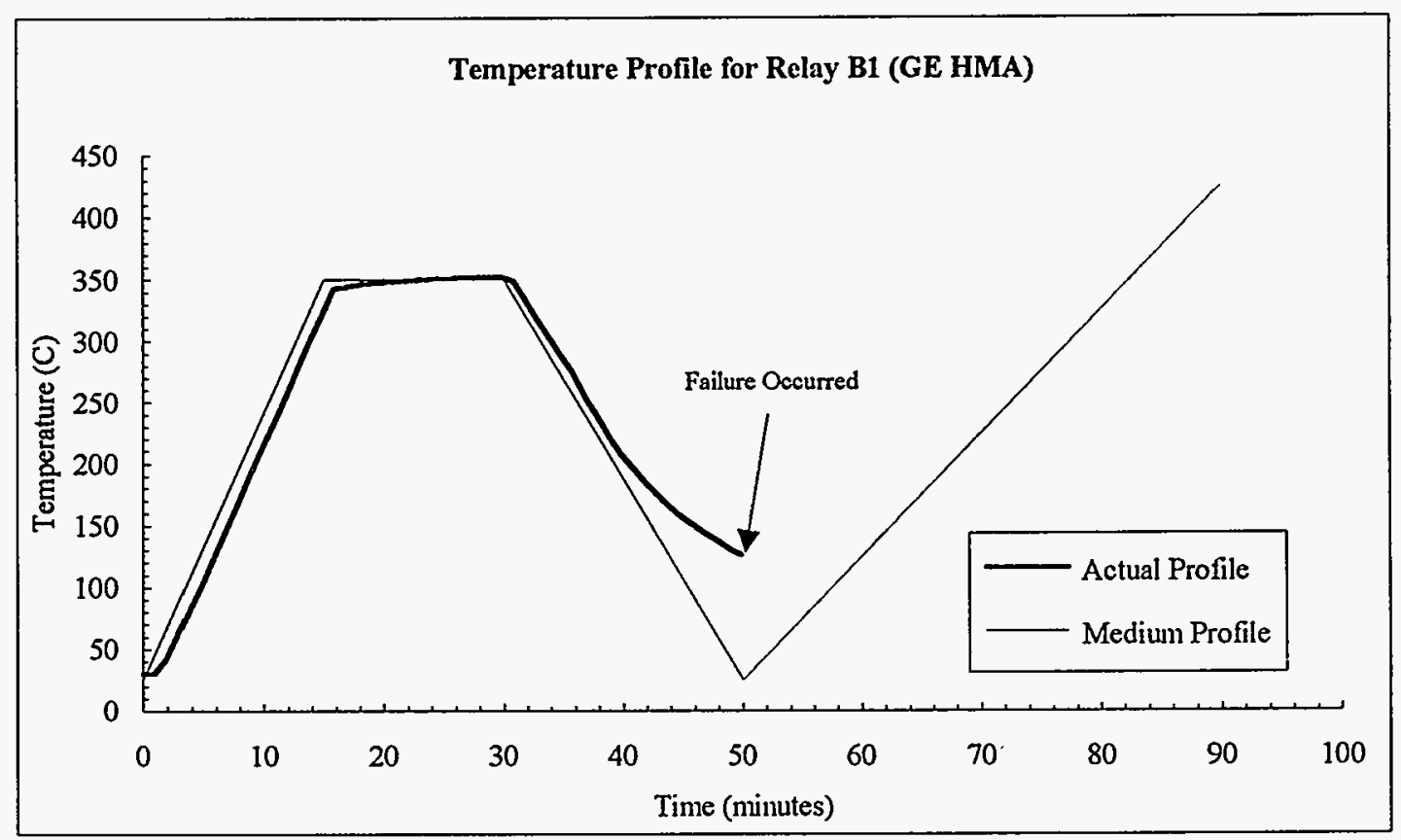

Figure A-7 SCETCh temperature exposure for relay BI

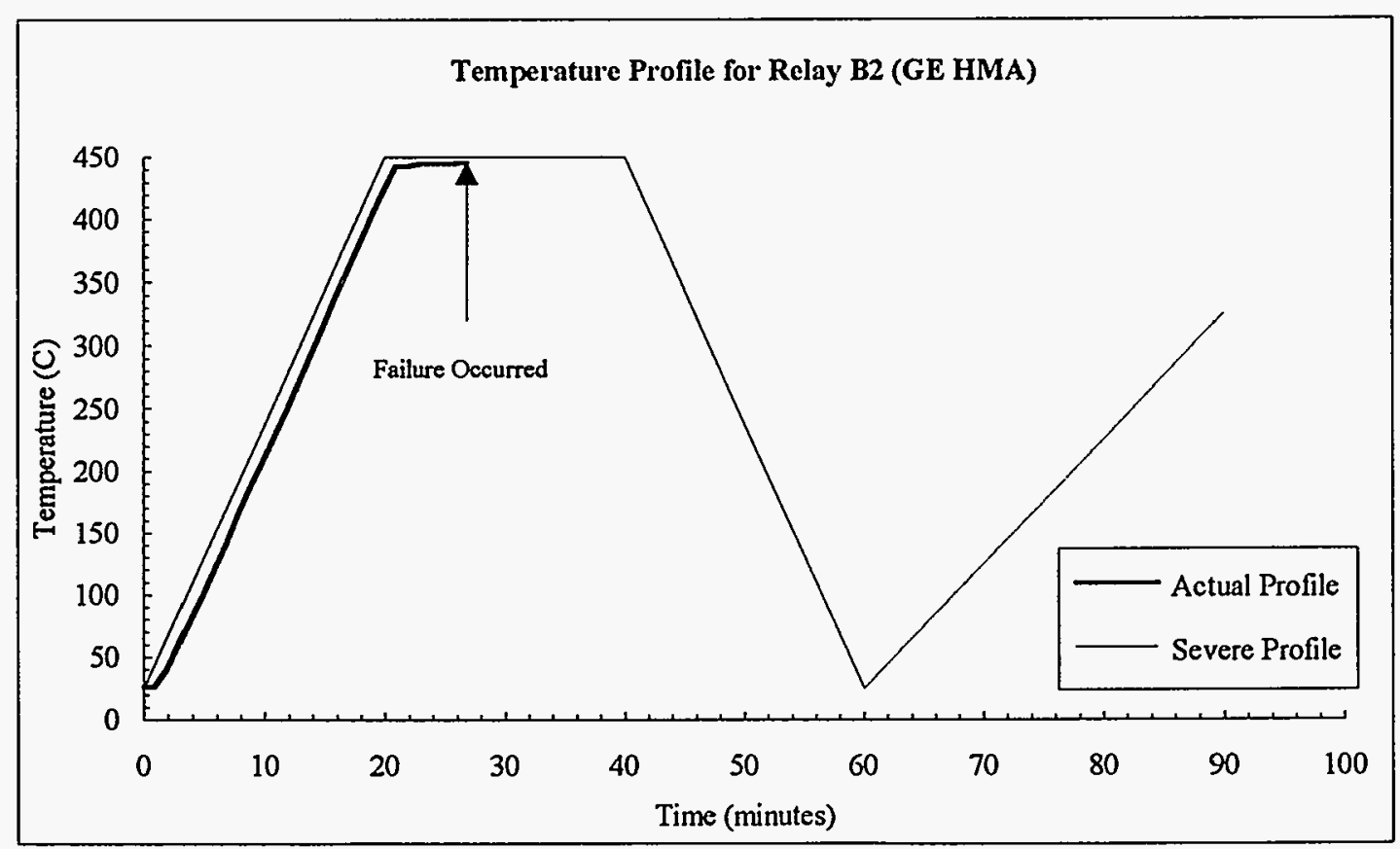

Figure A-8 SCETCh temperature exposure for relay B2 


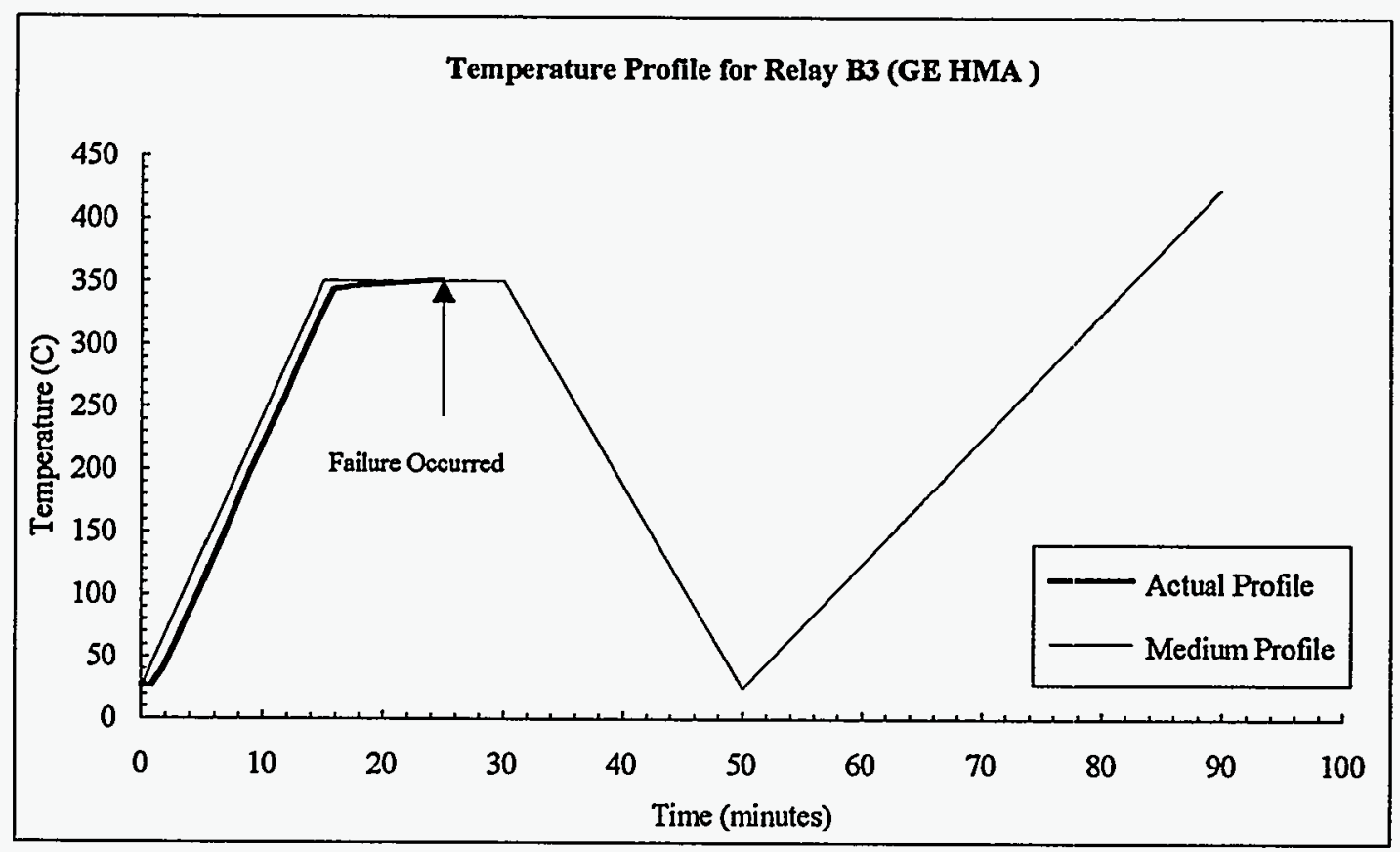

Figure A-9 SCETCh temperature exposure for relay B3

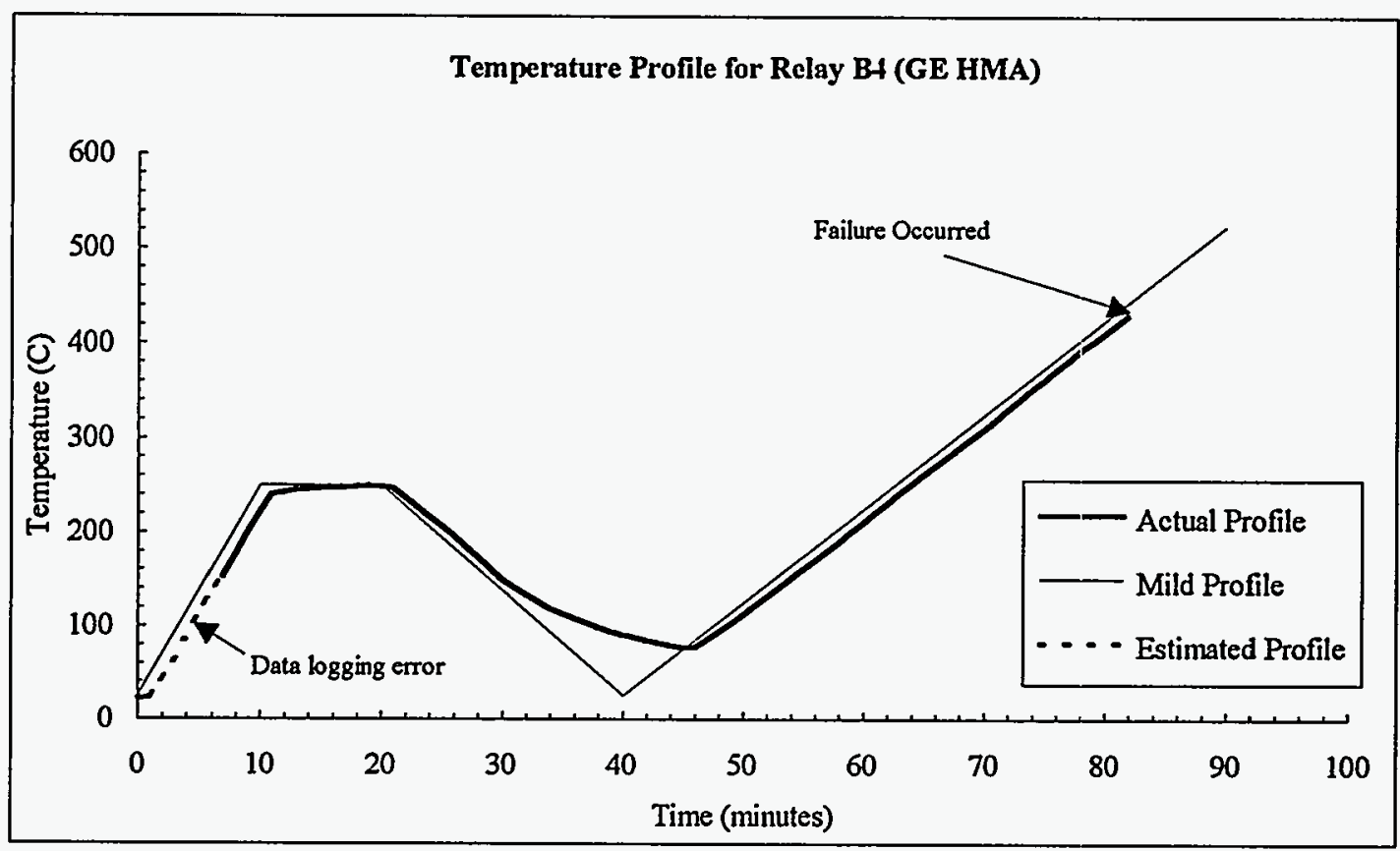

Figure A-10 SCETCh temperature exposure for relay B4 


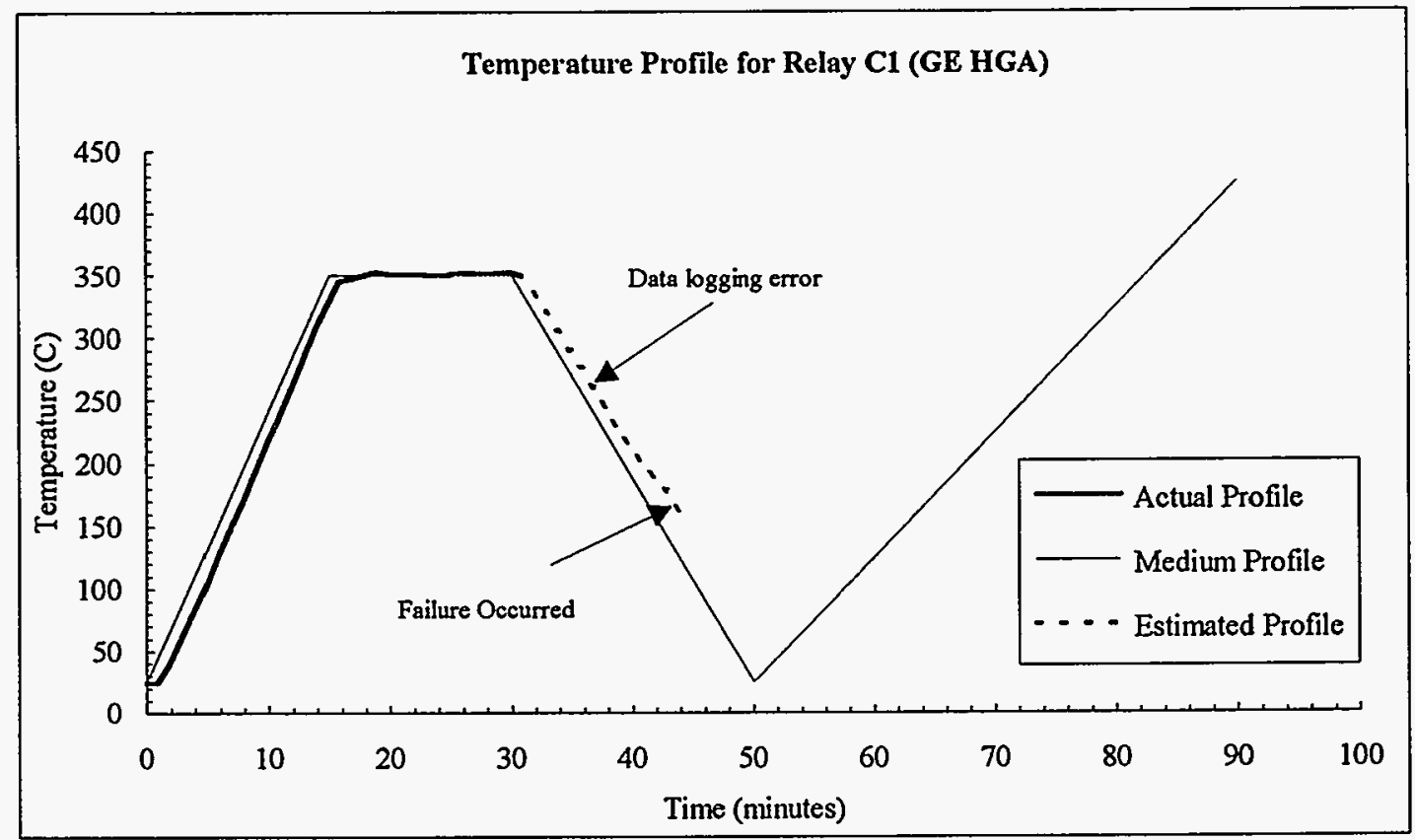

Figure A-11 SCETCh temperature exposure for relay $\mathrm{Cl}$

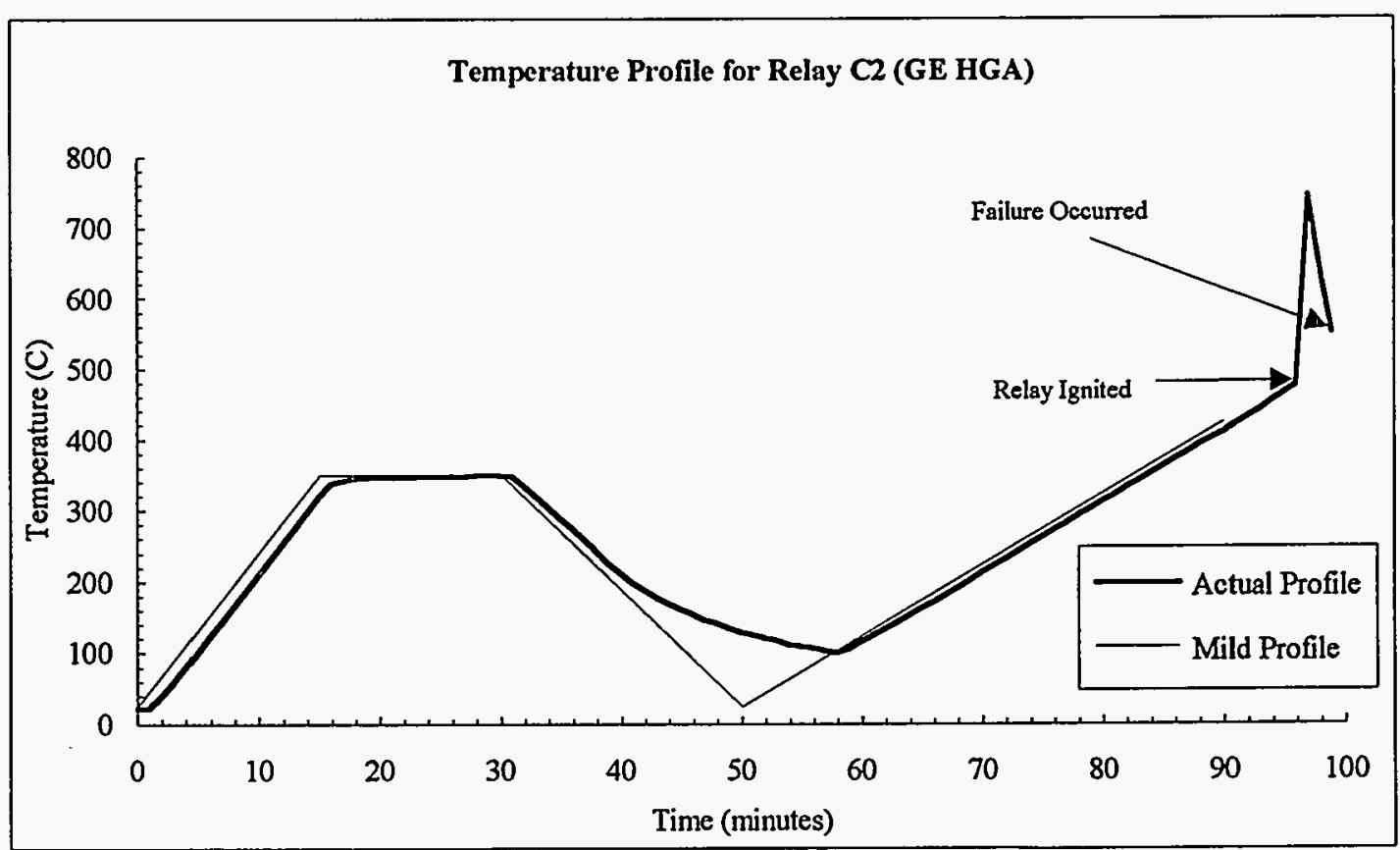

Figure A-12 SCETCh temperature exposure for relay C2 


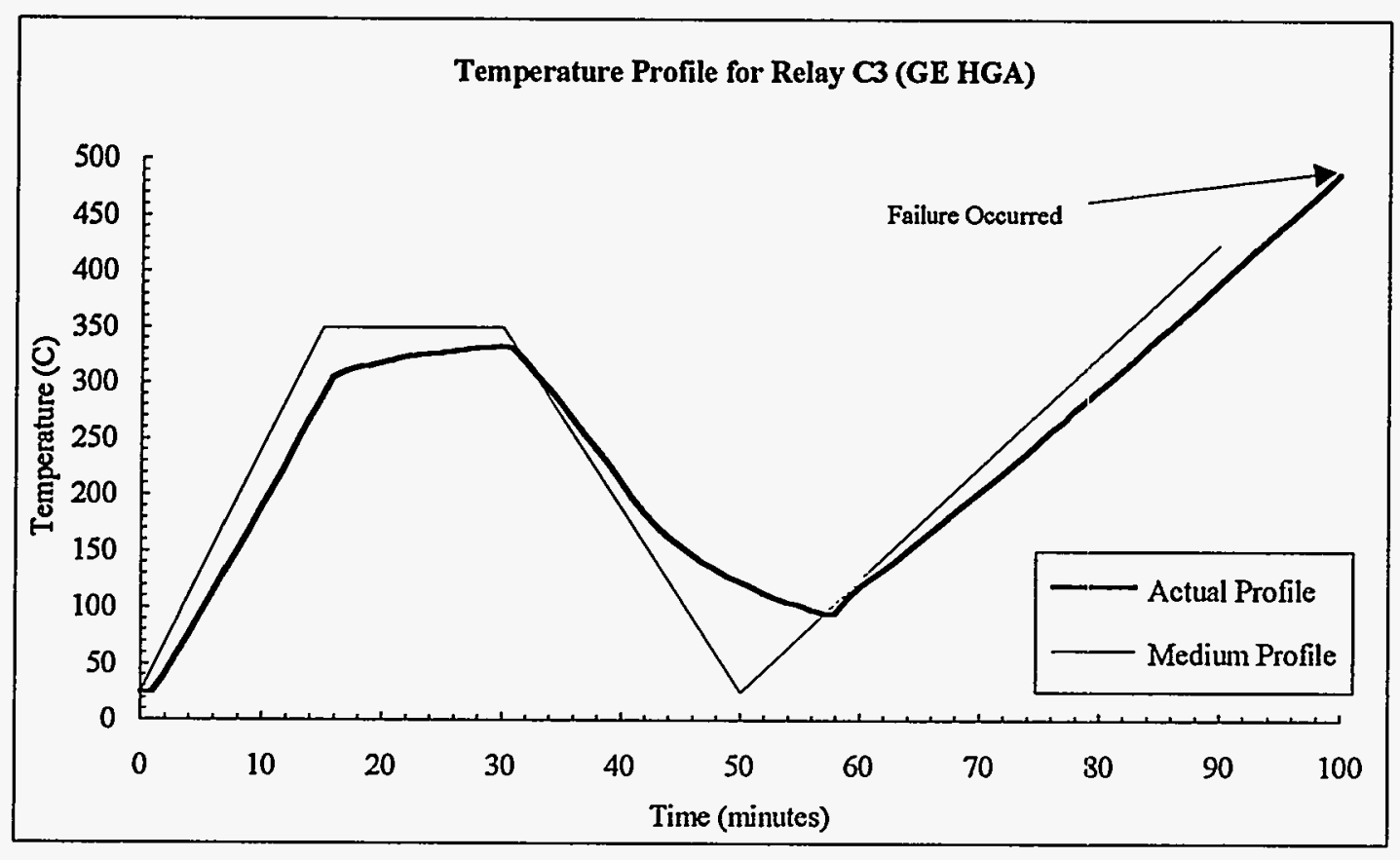

Figure A-13 SCETCh temperature exposure for relay C3

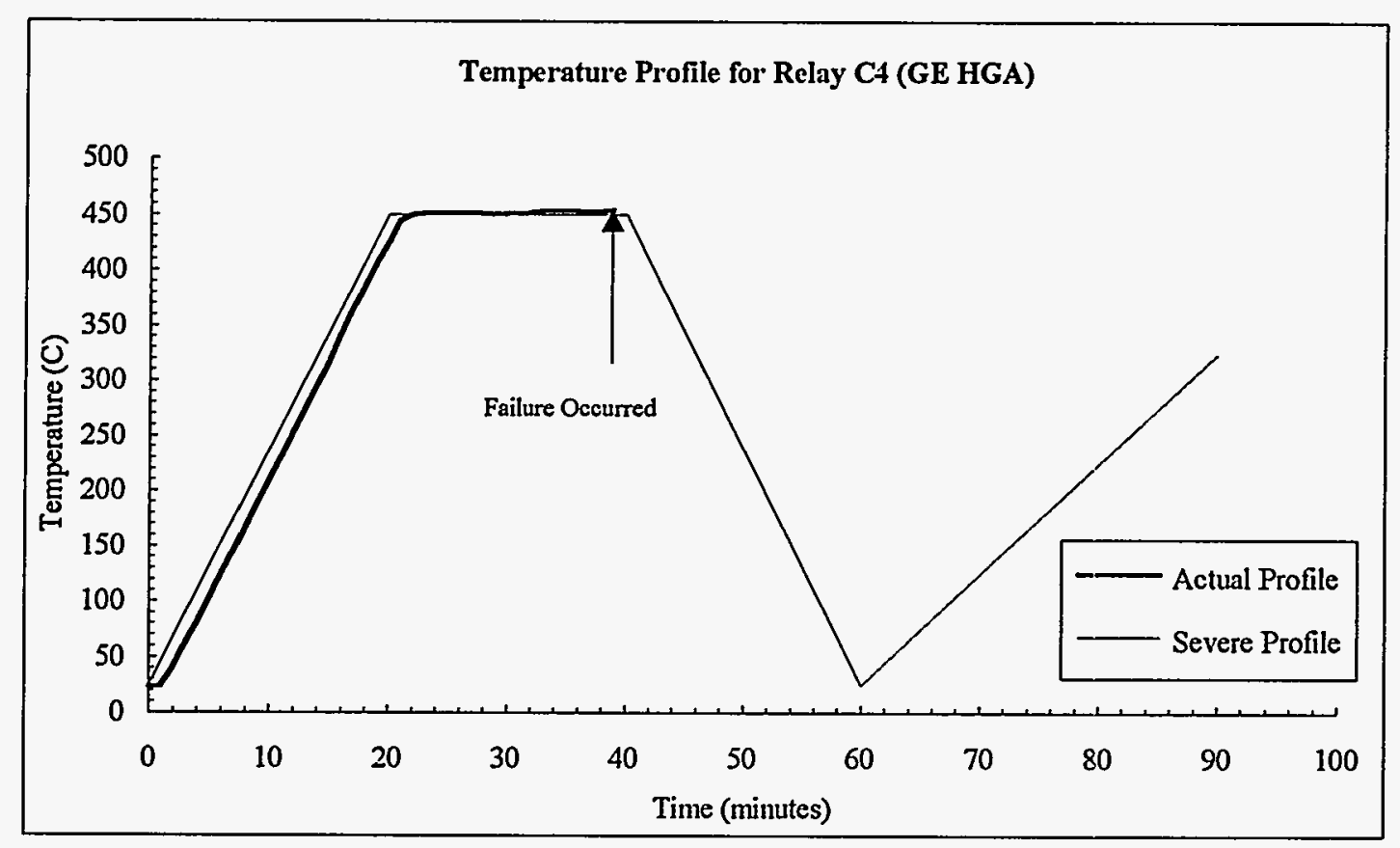

Figure A-14 SCETCh temperature exposure for relay C4 


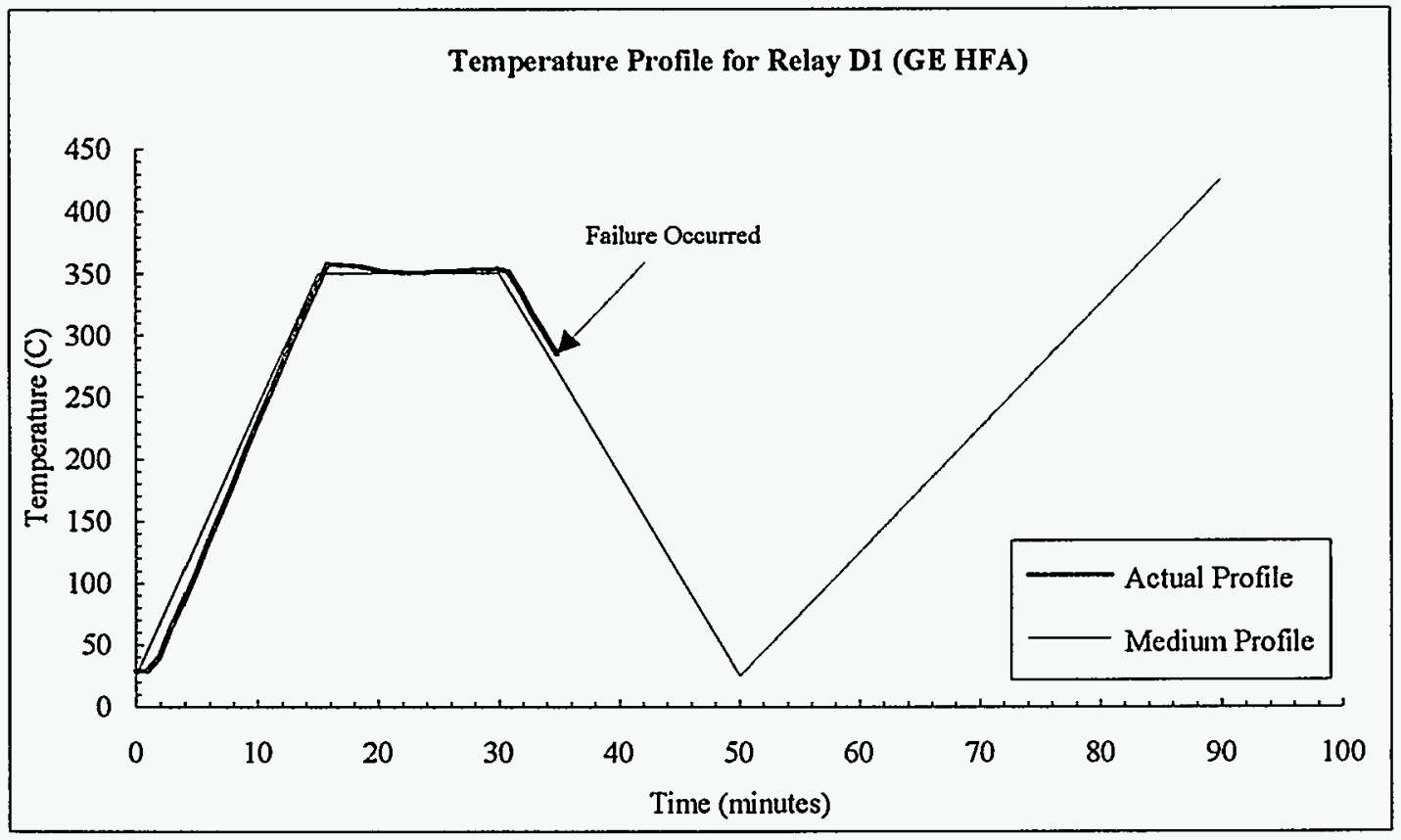

Figure A-15 SCETCh temperature exposure for relay D1

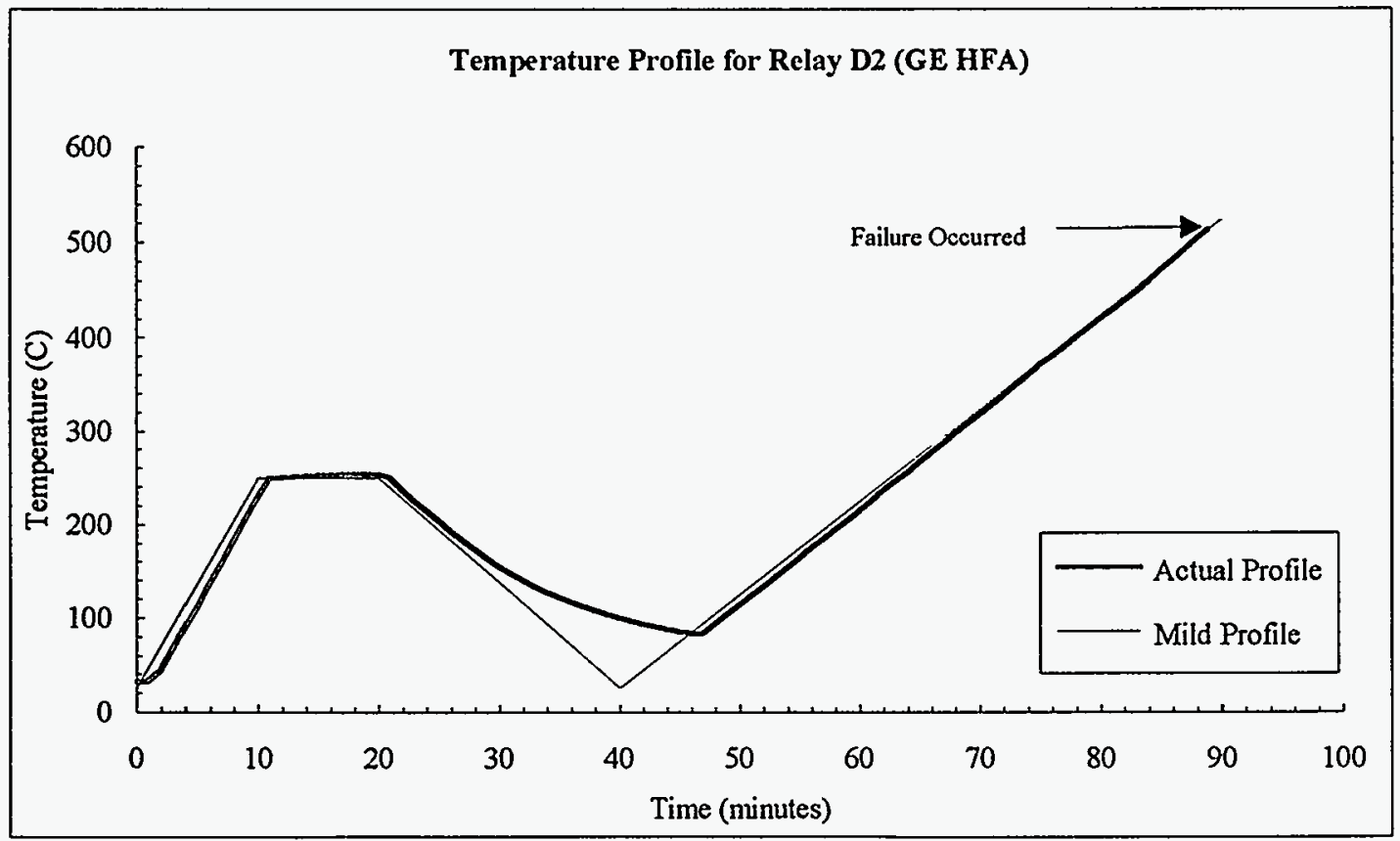

Figure A-16 SCETCh temperature exposure for relay D2 


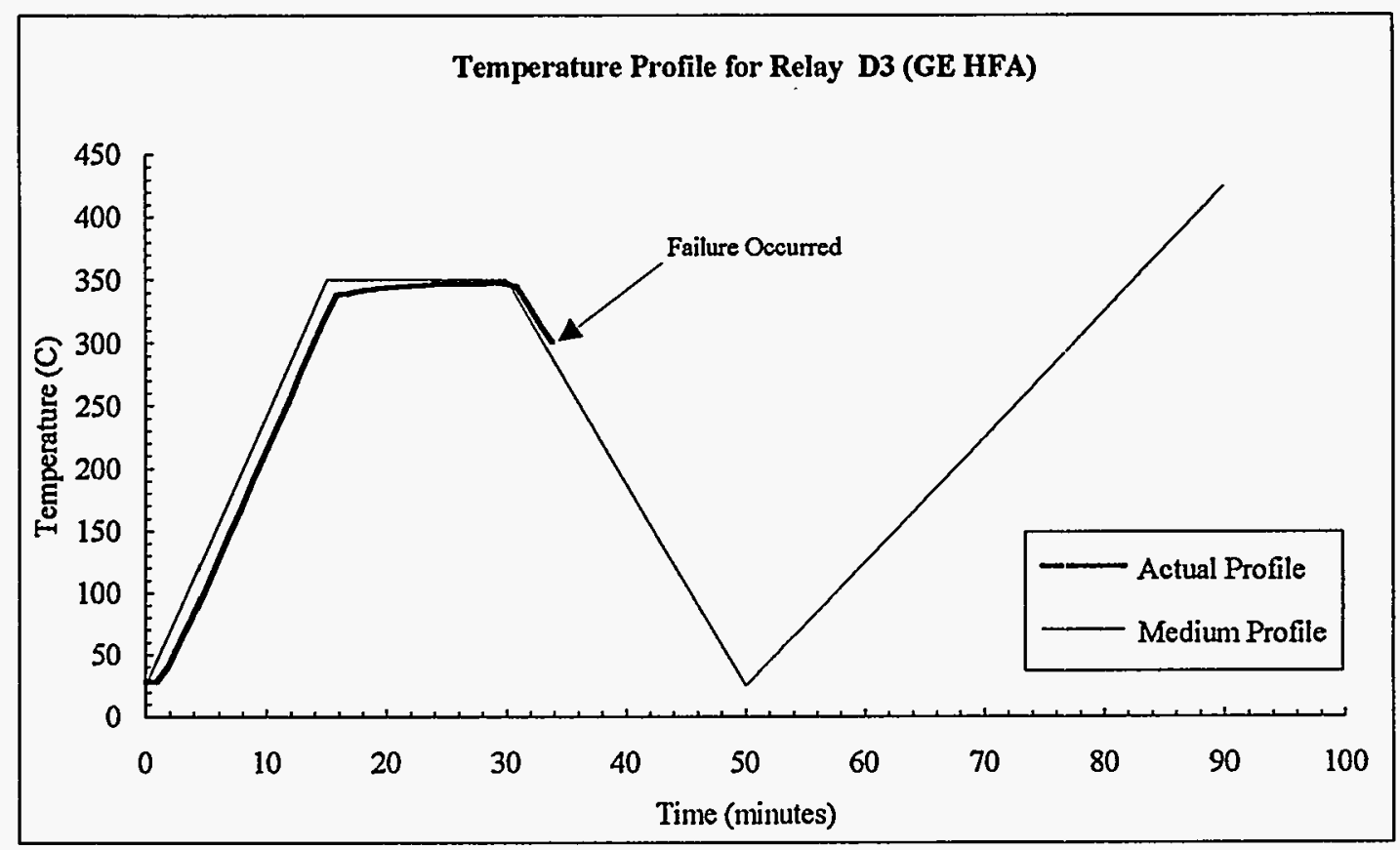

Figure A-17 SCETCh temperature exposure for relay D3

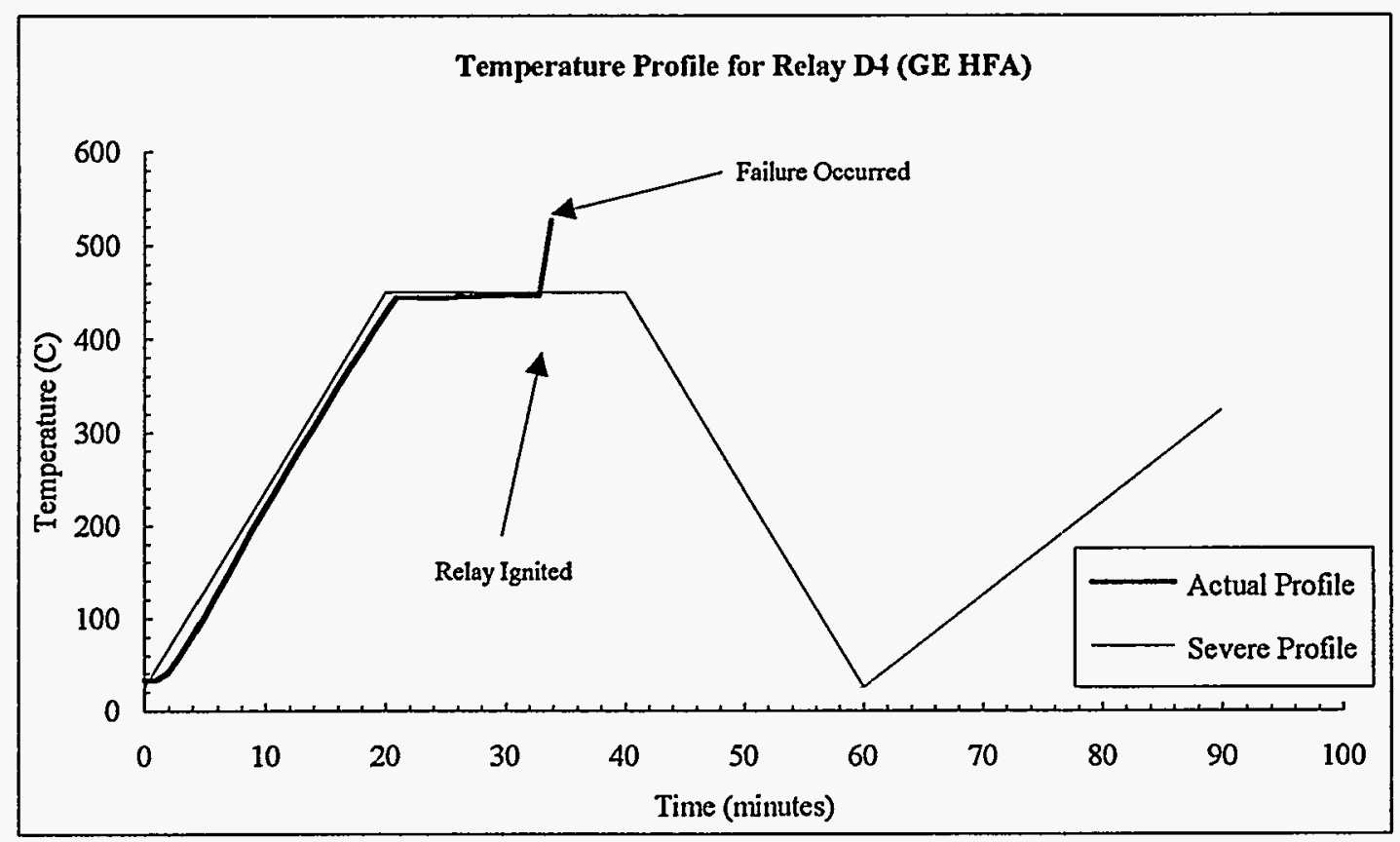

Figure A-18 SCETCh temperature exposure for relay D4 


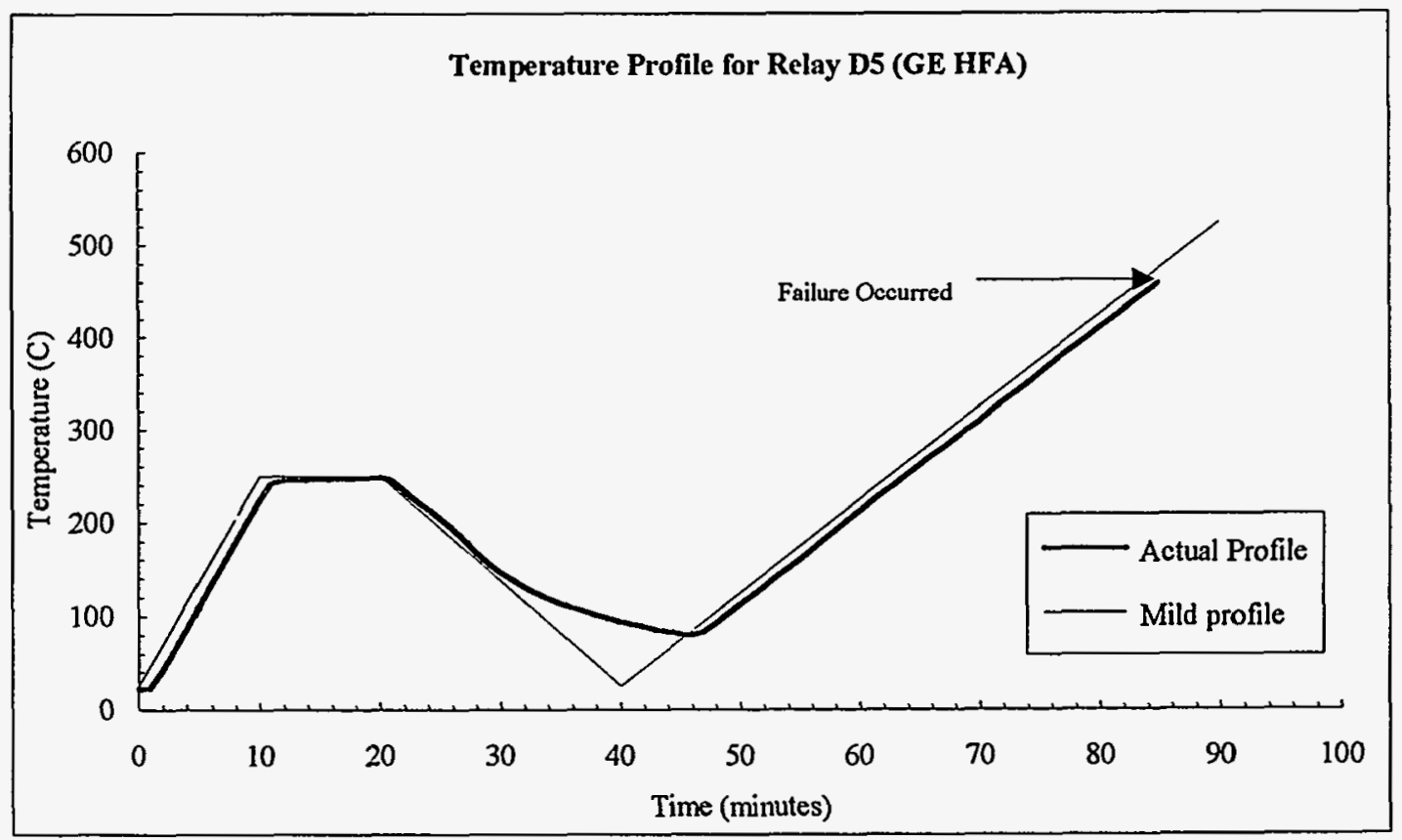

Figure A-19 SCETCh temperature exposure for relay D5 


\begin{tabular}{|c|c|}
\hline $\begin{array}{l}\text { U.S. NUCLEAR REGULATORY COMMISSION } \\
\text { BIBLIOGRAPHIC DATA SHEET } \\
\text { (See instructions on the reverse) }\end{array}$ & $\begin{array}{l}\text { 1. REPORT NUMBER } \\
\text { (Assigned by NRC. Add Vol., Supp., Rev., } \\
\text { and Addendum Numbers, if any.) } \\
\text { NUREG/CR-6220 } \\
\text { SAND94-0769 }\end{array}$ \\
\hline \multirow[t]{4}{*}{$\begin{array}{l}\text { 2.TITLEAND SUBTITLE } \\
\text { An Assessment of Fire Vulnerability for Aged Electrical Relays }\end{array}$} & \\
\hline & 3. DATE REPORT PUBLISHED \\
\hline & \begin{tabular}{|c|r|} 
MONTH & YEAR \\
March & 1995 \\
\end{tabular} \\
\hline & $\begin{array}{l}\text { 4. FIN OR GRANT NUMBER } \\
\text { A1833 }\end{array}$ \\
\hline \multirow[t]{2}{*}{$\begin{array}{l}\text { 5. AUTHOR(S) } \\
\text { R.A. Vigil*, S.P. Nowlen }\end{array}$} & $\begin{array}{l}\text { 6. TYPE OF REPORT } \\
\text { Technical }\end{array}$ \\
\hline & 7. PERIOD COVERED (Inclusive Dares) \\
\hline \multicolumn{2}{|c|}{$\begin{array}{l}\text { 8. PERFORMING ORGANIZATION - NAME AND ADDRESS (If NRC, provide Division, office or Region, U.S. Nuclear Regulatory Commission, and mailing address; if contractor, provide } \\
\text { name and malling address) } \\
\text { Sandia National Laboratories } \\
\text { Albuquerque, NM } 87185-0737 \\
\end{array}$} \\
\hline \multicolumn{2}{|c|}{$\begin{array}{l}\text { 9. SPONSORING ORGANIZATION - NAME AND ADDRESS (If NRC, tvpe "Same as above": if contractor, provide NRC Division, Office or Region, U.S. Nuclear Regulatory Commission, } \\
\text { and malling address.) }\end{array}$} \\
\hline \multicolumn{2}{|c|}{$\begin{array}{l}\text { Division of Engineering Technology } \\
\text { Office of Nuclear Regulatory Research } \\
\text { U.S. Nuclear Regulatory Commission } \\
\text { Washington, DC 20555-0001 } \\
\text { 10. SUPPLEMENTARY NOTES }\end{array}$} \\
\hline \multicolumn{2}{|l|}{ 10. SUPPLEMENTARY NOTES } \\
\hline \multicolumn{2}{|c|}{$\begin{array}{l}\text { This report details testing to assess the impact of aging on the fire vulnerability } \\
\text { of Agastat and General Electric relays. Both aged and unaged relays were tested. } \\
\text { Aged relays were subjected to operational cycling under rated load and thermally } \\
\text { aged for sixty days. All relays were exposed to one of three different fire } \\
\text { temperature profiles in the Severe Combined Environments Test Chamber located at } \\
\text { Sandia National Laboratories. The ability to operate properly in the given fire } \\
\text { environment was monitored. Results for the aged and unaged relays were examined } \\
\text { to determine the impact of aging on the relays' ability to sustain operation under } \\
\text { the test conditions. Overall results indicated that the aged relays' performance } \\
\text { was not significantly different from that of the unaged relays. }\end{array}$} \\
\hline \multirow[t]{6}{*}{$\begin{array}{l}\text { 12. KEY WORDS/DESCR!PTORS (List words or phrases that will assist researchers in locating the report.) } \\
\text { aging, relays, fire vulnerability }\end{array}$} & $\begin{array}{l}\text { 13. AVAILABILITY STATEMENT } \\
\text { unlimited }\end{array}$ \\
\hline & 14. SECURITY CLASSIFICATION \\
\hline & $\begin{array}{l}\text { (This Pagel } \\
\text { unclassified }\end{array}$ \\
\hline & $\begin{array}{l}\text { (This Report) } \\
\text { unclassified }\end{array}$ \\
\hline & 15. NUMBER OF PAGES \\
\hline & 16. PRICE \\
\hline
\end{tabular}

